\title{
The Simulation of Urban-Scale Evacuation Scenarios with application to the Swinley Forest Fire
}

\author{
Anand Veeraswamy ${ }^{1}$, Edwin R Galea ${ }^{1}$, Lazaros Filippidis ${ }^{1}$, Peter J Lawrence ${ }^{1}$, Simo Haasanen ${ }^{1}$, \\ Robert J Gazzard ${ }^{2}$ and Thomas E L Smith ${ }^{3}$ \\ ${ }^{1}$ Fire Safety Engineering Group \\ University of Greenwich \\ London SE10 9LS \\ United Kingdom \\ ${ }^{2}$ Forestry Commission England \\ Bucks Horn Oak \\ Surrey GU10 4LS \\ United Kingdom \\ ${ }^{3}$ Department of Geography \\ King's College London \\ London WC2R 2LS \\ United Kingdom
}

\begin{abstract}
Forest fires are an annual occurrence in many parts of the world forcing large-scale evacuation. The frequent and growing occurrence of these events makes it necessary to develop appropriate evacuation plans for areas that are susceptible to forest fires. The buildingEXODUS evacuation model has been extended to model large-scale urban evacuations by including the road network and open spaces (e.g. parks, green spaces and town squares) along with buildings. The evacuation simulation results have been coupled with the results of a forest fire spread model and applied to the Swinley forest fire which occurred in Berkshire, UK in May 2011. Four evacuation procedures differing in the routes taken by the pedestrians were evaluated providing key evacuation statistics such as time to reach the assembly location, the distance travelled, congestion experienced by the agents and the safety margins associated with using each evacuation route. A key finding of this work is the importance of formulating evacuation procedures that identifies the threatened population, provides timely evacuation notice, identifies appropriate routes that maintains a safe distance from the hazard front thereby maximising safety margins even at the cost of taking longer evacuation routes. Evacuation simulation offers a means of achieving these goals.
\end{abstract}

KEYWORDS: urban evacuation, evacuation simulation, wildfire, forest fire, disaster management, GIS

\section{$1 \quad$ Introduction}

Forest fires (also referred to as wildfires and bushfires) are an annual occurrence in many parts of the world causing massive damage to the natural and built environments, endangering lives and forcing the large-scale evacuation of entire residential areas and business and industrial facilities. Recent examples include the Fort McMurray fires (The Globe and Mail, 2016) in Canada (May 2016) which extended over an area of 590,000 hectares of Alberta involving over 4,000 fire fighters and other emergency personnel and resulted in the loss of 2,000 structures, the forced evacuation of 88,000 people and damage estimated at \$CAN3.6 billion (Regional Municipality of Wood Buffalo, 2016); the San Bernardino County Blue Cut fires in California (August 2016) involving more than 2,600 fire fighters, resulting in the loss of over 100 family residences (Incident Information System, 2016) and requiring mandatory evacuation calls to over 34,000 homes with more than 82,000 people, ranging from a ski resort to 
the entire town of Phelan with more than 14,000 residents (Chicago Tribune, 2016); and the Hafia Israel fires (BBC News, 2016), resulting in the evacuation of some 80,000 people from homes, schools, kindergartens, universities, a hospital for the aged and prisons (BBC News, 2016 and The New York Times, 2016), police and emergency services went door to door to alert people on the need to evacuate and the affected population evacuated on foot and by car (The New York Times, 2016).

One of the world's worst wildfires in living memory are the Black Saturday bushfires of Victoria Australia (February 2009) which claimed the lives of 173 people, burnt 430,000 hectares of land, 2000 properties and 61 businesses, with an estimated cost of \$AUS4 billion (Teague et al. 2009). Rather than a single fire there were over 47 fires scattered across the State that had the potential to become severe, five of which claimed people's lives - the most costly was the Kilmore East fire that claimed 119 lives. The Country Fire Authority (CFA) engaged approximately 12,000 CFA fire fighters and over 1000 operational vehicles to fight the fires with the support of an additional 1000 fire fighters from the Department of Sustainability and the Environment (DSE). One of the issues to come out of the Royal Commission held to investigate the response to the fires concerned the advice given to the community on whether or not they should evacuate, the so-called 'stay or go' policy, more correctly stated as, 'Prepare, Stay and Defend or Leave Early'. The Commission concluded that the authorities had placed insufficient emphasis on the risks of staying and defending ones property and that the safest option is always to leave early. The Commission recommended that, ' $\ldots$ the State introduce a comprehensive approach to evacuation so that this option is planned, considered and implemented when it is likely to offer a higher level of protection than other contingency options .....' (Recommendation 5) (Teague et al., 2010).

The threat posed by wildfires is not restricted to countries with hot climates. A large number of wildfires occur in Great Britain every year. In the past four years there have been on average 45,000 wildfires each year attended by the fire and rescue services in Great Britain (Crowhurst, 2015). Furthermore, warmer and drier conditions, and more frequent and longer-lasting heatwaves also raise the risk of wildfires. This risk is compounded by the UK's high population density, which means that fires are more likely to encroach into urban environments, posing a significant threat to life. Forest fires can spread rapidly affecting built-up areas in its path at different times depending on the speed and direction of the fire spread, which in turn is dependent on a number of factors such as the wind speed and direction, nature of terrain and available fuel in the path of the fire (BBC News, 2016, Chicago Tribune 2016, Regional Municipality of Wood Buffalo, 2016, Teague et al., 2009, Teague et al., 2010 and The New York Times, 2016).

It is clear that wildfire often requires the evacuation of large numbers of people from large areas and potentially over great distances. The frequent and growing occurrence of these events suggests that it is necessary to develop appropriate evacuation plans for areas that are susceptible to wildfires.

This paper provides an overview of the development of the EXODUS urban-scale evacuation modelling system (Chooramun et al., 2012, Galea et al., 2008, Galea et al., 2011, Pretorius et al., 2013 and Siddiqui and Gwynne, 2012), and describes the application of the software to a case study involving the Swinley Forest fire that occurred near Bracknell in Berkshire, UK on May 02, 2011. As part of this work, the 
paper also describes the loose coupling of the EXODUS software to the Prometheus wildfire simulation tool (Tymstra et al., 2010). It is suggested that the developed methodology could be utilised by authorities to formulate evacuation procedures before an incident takes place based on historic data (e.g. past wildfires, floods, earthquakes, etc.) and also has scope to be applied during incidents by providing first responders with key evacuation related information.

\section{$2 \quad$ Literature Review}

When planning an evacuation for a community threatened by wildfire, it is essential for civil protection authorities to know what areas will be affected due to a fire, when the areas will become untenable, how long it will take occupants in these regions to evacuate and how long it will take occupants to reach a designated place of safety. To this end, fire simulation tools such as Prometheus (Tymstra et al., 2010) and Phoenix (Tolhurst et al., 2008) have been developed that attempt to predict the spread of the wildfire. These models take into consideration the nature of the available fuel, the terrain and the atmospheric conditions and provide an estimation of the direction and rate of spread of the fire front.

While this type of information is necessary to assess the level of risk associated with each region it is not sufficient to optimally determine how and when to warn the population appropriately, how to allocate available resources (first responders, fire fighters and staff at assembly locations) and most importantly to formulate an effective evacuation strategy which involves safe routes that occupants can take to the designated assembly locations. To do this also requires an ability to predict the evacuation movement and behaviour of city sized populations of people measuring in the tens of thousands if not hundreds of thousands.

Several evacuation models have been developed that attempt to simulate large scale evacuation situations resulting from floods (Durst et al., 2014) and earthquakes (D'Orazio et al., 2014). MATSIM, a transport simulation tool has been used to perform pedestrian evacuation simulation at city scale involving over a million agents (Lämmel, 2008). The road network is imported from OpenStreetMaps (Neis et al., 2011) and represented in MATSIM as a directed graph with the streets being represented as links or arcs connecting the vertices or nodes, which represent a point on the earth's surface. Network change events such as altering the state of a link from traversable to nontraversable occurs dynamically as the simulation runs. Initially all agents utilise a shortest path to the refuge areas. However, the Nash equilibrium (Osborne and Rubinstein, 1994) approach is employed where agents attempt to find a route that is optimal in terms of the time required to reach the destination in each successive iteration taking into account congestion levels encountered on the evacuation routes. Over many iterations this approach provides an estimation of the overall shortest evacuation time which could represent an evacuation where agents have been trained or guided so as to follow a pre-determined procedure. This approach has been used to model the pedestrian evacuation simulation of the entire city of Padang, Indonesia involving 320,000 agents in response to a tsunami (Lämmel et al., 2010) and a part of Zurich involving 165,571 agents in response to a flood (Lämmel, 2008). A similar approach has been used to model large-scale multi-modal (i.e. involving pedestrians, buses, railway and cars) evacuation simulation of Hamburg-Wilhelmsburg, Germany consisting of 50,601 inhabitants in response to a flood (Klüpfel, 2014). Travel mode 
change options were also implemented allowing for example agents to walk to a bus stop, take a bus to the train station and take a train to a safe location.

The PedGo simulation tool has been used by (Klüpfel, 2014) to perform pre-event and post-event pedestrian simulations of a popular event that attracted a very large number of visitors $(250,000)$ in Burgdorf, Switzerland. The actual pedestrian traffic flow and congestion observed during the event was significantly different (less congestion was observed than predicted) from the pre-event simulations mainly because of an underestimation of response times and overestimation of the number of people. When these factors were modified accordingly the post-event simulations provided a good agreement with the observations during the actual event. This illustrates the intricacies in large scale evacuations - small deviations from assumptions of initial conditions can lead to large differences in the simulation results when compared to the actual event.

The simulation of large-scale evacuation requires the inclusion of a number of human behaviour aspects into the modelling process. According to (Osaragi et al., 2013) the following factors are key to model large scale evacuations following an earthquake: spatiotemporal distribution of people at the time of the earthquake, time at which people start evacuating, decision to head to a temporary refuge location or to the official refuge location and routes that people choose to use (familiar versus safe routes avoiding affected areas). A study of human behaviour during earthquakes, both within structures and outside, (Bernardini et al., 2014) has identified the following behaviours; attraction to safe areas, herding behaviour, attraction between members of the same group, keeping a safe distance from buildings and group formation. They also determined the average speeds and distances between members of the same evacuating group and represented these behaviours in a simulation tool by modifying the social force model (Helbing and Johansson, 2013).

A city scale evacuation model utilising a potential map system for navigation has been developed (Nishino et al., 2011) where agents travel towards refuge locations taking paths that they perceive to be safe while staying away from hazards such as fire. A flood simulation model was coupled to an evacuation simulation model (Mordvintsev et al., 2014) where agents could assume one of several states such as idle, running, safe and drowned. Agents followed a potential map avoiding static obstacles as well as nontraversable flooded areas to reach safe refuge areas.

While several wildfire evacuation models have been developed (Cova and Johnson, 2002 and Singh et al., 2016), most of these are vehicular models (Cova and Johnson, 2002 and Singh et al., 2016) thus ignoring pedestrian movement. Furthermore, few if any of the wildfire evacuation models are coupled with fire simulation tools and when this is done it is generally for visualisation purposes only as in the Singh et al model (Singh et al., 2016) which utilises output from the Phoenix fire simulation tool (Tolhurst et al. 2008). Coupling agent based urban scale evacuation models to wildfire simulation tools enables the identification of, the available time for safe evacuation, which routes become untenable and at what time, population exposure doses to harmful fire products during evacuation and safety margins associated with alternative evacuation strategies.

Thus while evacuation models have been developed that attempt to simulate large scale evacuation situations most of these are vehicular evacuation models or adapt vehicle simulation tools to model pedestrian evacuation utilising only the vehicular network 
thus ignoring areas/routes that could be utilised by pedestrians and utilise a macroscopic model for representing space and agent movement. Furthermore, current urban scale agent based evacuation modelling tools are generally not integrated with disaster management systems. As a result, disaster managers do not have an easy means to test evacuation procedures during pre-incident planning or receive real time support on optimal evacuation procedures to adopt during an ongoing incident. Integrating evacuation simulation tools with disaster management systems to produce a Common Operating Picture (COP) provides valuable evacuation decision support functionality for disaster managers to assist in the co-ordination and management of disasters.

Large scale disasters bring together diverse organizations which produce large quantities of heterogeneous data. This makes it vital to utilise Information and Communications Technology (ICT) to co-ordinate disaster management thereby making it more effective. Disaster management systems have various components such as organisation registry, missing persons registry, shelter registry (camps, hospitals, schools), request management system, inventory management system, etc (Careem et al., 2007 and Van de Walle and Turoff, 2008). Current disaster management systems such as Sahana (Careem et al., 2006 and Currion et al., 2007) typically utilise a Geographic Information System (GIS) to capture, store, analyse and manage geographically referenced data to provide a coherent system for incident commanders. They also rely greatly on open standards to enable communication between diverse systems. However, most currently available disaster management systems do not presently integrate external simulation tools. In order for external simulation tools to be integrated with disaster management systems the simulation tools need to be able to read and produce outputs using open standards.

While the CEMPS (Configurable Emergency Management and Planning Simulator) simulator (Silva and Eglese, 2000) comes close to addressing this problem by coupling a traffic simulation model with ESRI's GIS-ARC/INFO, nothing currently exists that couples agent based evacuation models with incident management systems.

The approach adopted in this paper differs from previous work by providing a loose coupling between the evacuation simulation tool and disaster management system with the focus being on pedestrian rather than vehicle traffic simulation in response to large scale disasters. The agent based evacuation simulation tool buildingEXODUS while primarily used for building evacuation applications (Chooramun et al., 2012, Galea et al., 2008 and Galea et al., 2011) has also been used to simulate large crowds in external environments (Pretorius et al., 2013 and Siddiqui and Gwynne, 2012). As part of the EU FP7 project IDIRA (Fire Safety Engineering Group, 2015b), the buildingEXODUS software was adapted to model large scale external spaces involving not simply the road network as current large scale evacuation models do (Lämmel et al., 2008, Lämmel et al., 2010) but also involving other objects utilised by pedestrians such as buildings, open spaces, paths, etc. It also utilised open GIS standards such as shapefiles (Xia and Wei, 2008), Web Map Service (Li et al., 2010) and Web Feature Service (Peng and Zhang, 2004) and Free and Open Source Software (FOSS) such as such as PostGIS spatial extensions (Obe and Hsu, 2011) for PostgreSQL database (Drake and Worsley, 2002), OpenLayers (Perez, 2012) a JavaScript library for displaying map data in web browsers to develop a user friendly GUI that the strategic (command and control centres) and tactical (on-scene) commanders could utilise to specify input data for the EXODUS simulation such as: areas to evacuate, refuge locations, non-traversable areas and distribution and attributes of pedestrian population. The GUI also enables 
commanders to run simulations and analyse the results in order to determine the efficiency of the various evacuation options available. In this way the EXODUS software was integrated within the web based GIS disaster management system (COP) developed as part of the IDIRA project. The developed system was found to be a valuable decision support tool for the people/organisations involved in disaster management.

\section{The EXODUS Large Scale Evacuation System}

The EXODUS large scale evacuation modelling system is an agent based evacuation model capable of simulating the evacuation of large populations - measured in the hundreds of thousands - in large scale environments - measuring many square kilometres. It is based on the buildingEXODUS (Chooramun et al., 2012, Galea et al., 2008, Galea et al., 2011, Pretorius et al., 2013 and Siddiqui and Gwynne, 2012) software and consists of three components; urbanEXODUS, webEXODUS and the EXODUS engine as shown in Figure 1. Each of these are briefly described in the following section.

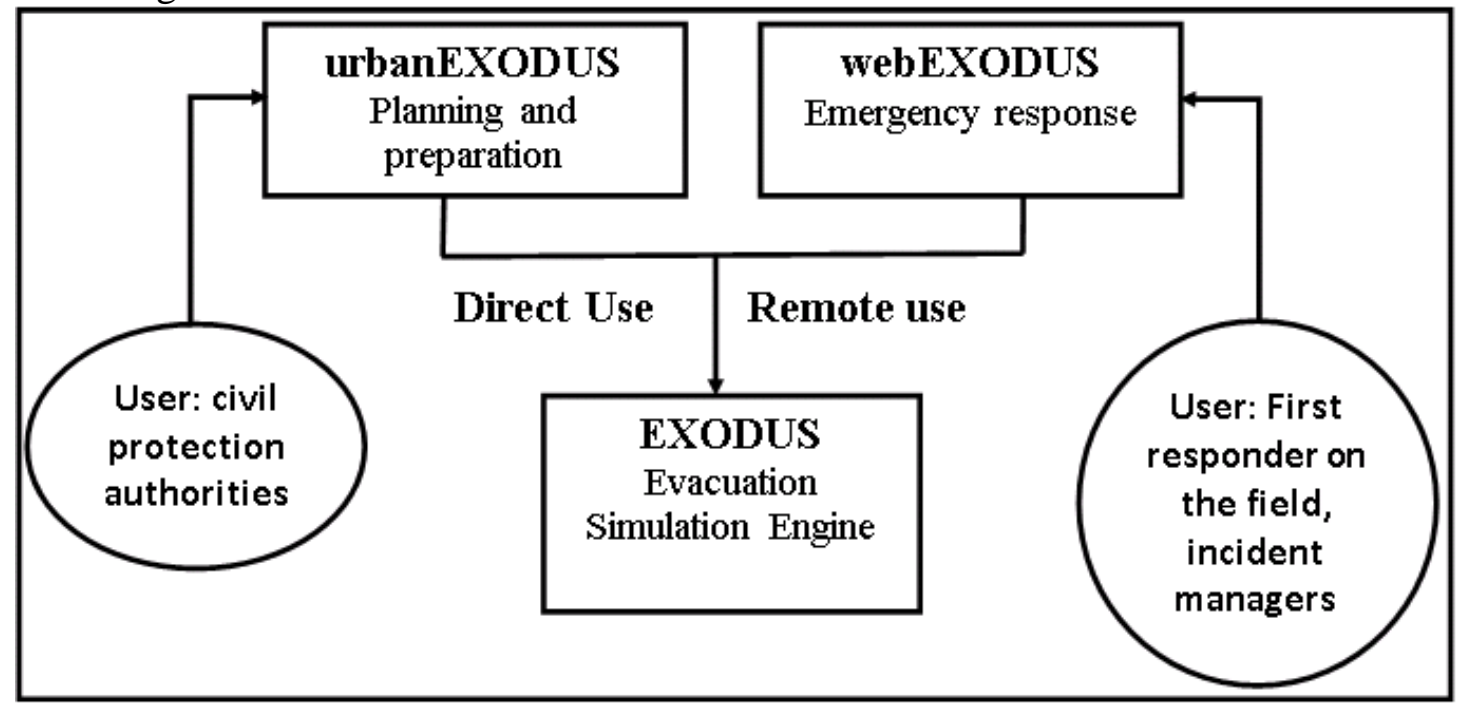

Figure 1: Diagram showing the usage of urban and webEXODUS

\section{1 urbanEXODUS}

A desktop interface, urbanEXODUS, was developed to enable the EXODUS engine to easily represent large scale urban spaces. It is capable of receiving geospatial vector data from an OSM XML (Neis et al., 2012) file and converting it into a virtual representation of space that is suitable for modelling pedestrian evacuation. It is also capable of producing simulation output in the form of shapefiles that can be published to GIS servers thus aiding visualisation of simulation output on web based GIS interfaces. The main use of urbanEXODUS is pre-incident during the planning and preparation phase of a possible large scale evacuation by simulating various what-if evacuation scenarios.

While MATSIM only models the street network from an OSM XML file, urbanEXODUS models additional real world spatial objects that pedestrians may make use of during an evacuation including buildings, open spaces (public spaces, car parks, piers, parks, etc). Once the virtual environment is modelled within urbanEXODUS the user can then specify the population, hazards and procedural data, to define an evacuation scenario. In addition to generating an $\mathrm{xml}$ output file providing details of 
the evacuation simulation results, urbanEXODUS also generates the population density contours in a geospatial data format such as shapefiles (Xia and Wei, 2008) so these can be overlayed on baselayers such as Google Maps, OpenStreetMaps or Bing Maps on a browser.

\section{2 webEXODUS}

A portable GIS based web interface, webEXODUS, was developed to be utilised during an incident. It is connected to the evacuation simulation server over the Internet and can be accessed remotely via browsers on desktop PCs, tablets or smartphones. It can also be used during the planning and preparation phase similar to urbanEXODUS. However, it is primarily intended for use during an incident by strategic command in the command and control centre providing a generic data model to describe a variety of evacuation simulations and run these simulations on the remote evacuation server. By enabling the current tactical situation to be represented in the evacuation simulation and providing a set of tools to rapidly analyse the results the system assists strategic commanders decide which evacuation procedure to employ based on the situation as it unfolds.

webEXODUS requires the EXODUS geometry to have been prepared prior to the incident enabling end users to simply specify the evacuation scenario(s) they wish to consider during the actual incident. The evacuation scenarios can include expected (e.g. generated from census data) or observed (e.g. generated by local authorities) population levels and distributions, hazard locations (e.g. generated from model predictions or observational data from operatives in the field) and evacuation procedures. webEXODUS is connected to the EXODUS engine over the Internet and can initiate new simulations remotely. After completion of the simulation, it is possible to view the evacuation progress as population density contours on a standard browser. webEXODUS has been integrated with the IDIRA disaster management system. During an incident, it allows users in the command and control centre to publish the results of an evacuation scenario that is most representative of the ensuing event to the IDIRA COP, a component of the IDIRA system, that provides the incident commanders in the field a summary of the myriad components involved in the rescue and relief efforts following a large scale disaster. This information assists the commanders in the field to make informed decisions in coordinating the evacuation of people during disasters.

\subsection{EXODUS Engine}

The EXODUS engine (Chooramun et al., 2012, Galea et al., 2008, Galea et al., 2011, Pretorius et al., 2013 and Siddiqui and Gwynne, 2012) receives simulation inputs from urbanEXODUS or webEXODUS, performs the simulations and returns the results. Within the EXODUS engine agents are represented as individuals with each agent being defined by a set of attributes. The attributes broadly fall into four categories: physical (such as age, gender, agility, mobility), psychological (such as patience, drive, response time), experiential (such as distance travelled, time travelled, time waiting in congestion) and physiological (such as respiration rate, impact of narcotic and irritant gases, impact of heat). These attributes have the dual purpose of defining all occupants as individuals while allowing their progress and condition during the evacuation to be tracked. Agents can also be provided with itineraries which can modify their behaviour prior to and during the evacuation process. For example, an agent may decide to collect their children from school prior to starting to evacuate, or may need to undertake a number of tasks in their dwelling prior to starting to evacuate. 
The EXODUS engine is a hybrid model capable of utilising coarse node, fine node and continuous spatial representations (Chooramun et al., 2012). The coarse and fine node modes of the EXODUS engine have been utilised with the former providing quick preliminary results at a faster than real time rate and the latter providing more refined results but requiring longer run times. The coarse node model employs 'location estimation' techniques by estimating the location and spread of agents within the region. This is to partially compensate for inherent uncertainties associated with pure coarse node modelling thus improving the accuracy of the movement model and hence the overall predictions. It also allows for the calculation of population densities within sub-regions of the coarse nodes. The same technique is also utilised to record the number of people in $6 \mathrm{~m} \mathrm{X} 6 \mathrm{~m}$ grid cells which are used to produce a heat map showing population density contours. The coarse node model also employs varying walk speeds depending on whether the agent is traversing paved paths or off road paths. Junctions such as road junctions are modelled as special coarse nodes which can represent multidirectional flow.

\subsection{System Overview}

An overview of the utilisation of the three components - urbanEXODUS, webEXODUS and EXODUS engine during the preparation/planning and emergency responses phases of disaster management is provided in Figure 2. Sometime before an incident, the spatial data and hazard simulation data are provided as inputs to urbanEXODUS. The spatial data is currently in the form of an OSM XML file. The OSM data includes the coordinates of the geospatial objects as well as their description. For example the OSM data includes the co-ordinates of an object and includes a description identifying the type of object such as a building, road or park. urbanEXODUS reads the OSM data and builds a virtual representation of space to model pedestrian movement in it. The KML fire perimeter output from the fire spread model, Prometheus (Tymstra et al., 2010) was also provided as an input to urbanEXODUS. This helped identify the times at which critical areas in the modelled area became untenable due to fire.

During the planning and preparation phase, end users can then configure an evacuation scenario by specifying population and procedural data. Population data mainly includes the number of people in the region, their attributes and manner of their distribution. Procedural data includes the manner in which the population is to be alerted, population response times, identification of personal itineraries for the population and routes taken. The EXODUS engine receives the scenario input from urbanEXODUS and runs the simulation. During simulation, the EXODUS engine stores the population density contours as the simulation progresses at pre-defined time-steps in the form of Shapefiles. Upon completion of the simulation, the simulation results are transferred to urbanEXODUS. The key results include the overall evacuation times, individual evacuation times of each agent in the simulation along with other results such as congestion times and safety margins. The Shapefiles are stored on a GIS server thus allowing the simulation progress to be overlaid on basemaps using webEXODUS.

During the emergency response phase, webEXODUS could be utilised by strategic level incident commanders to view the results of the simulations performed during the planning and preparation phase thus assisting them to decide what evacuation procedure to employ. However, not all eventualities can be tested prior to an incident and hence incident commanders can also modify scenarios using the latest tactical information 
reflecting the current situation and rerun the simulation. The web interface of webEXODUS has been simplified so it can be utilised by those who are unfamiliar with evacuation simulation tools. After analysing different evacuation procedures, the incident commanders can publish the most suitable evacuation procedure to a disaster management system or COP (Prinz, 2014) which provides a Common Operational Picture in real-time, sharing disaster related information from all parties on strategic, tactical and operational levels. The evacuation simulation results published on the COP assists the tactical and operational commanders to manage the tactical implementation of the evacuation process by implementing a set of evacuation actions.

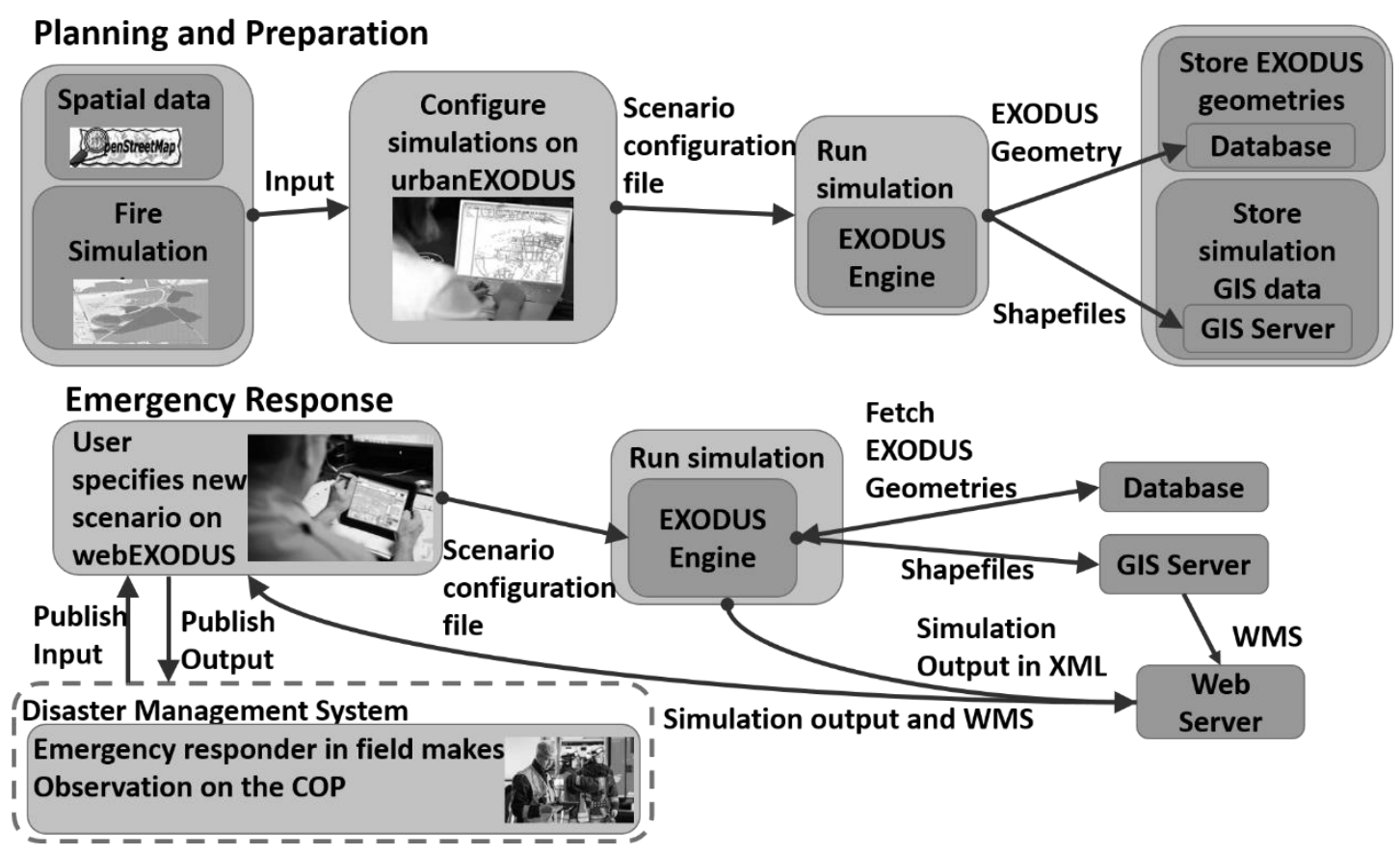

Figure 2: System overview depicting the use of urbanEXODUS during planning/preparation and webEXODUS during emergency response phases of a large scale incident.

\section{4 urbanEXODUS Application Example - Swinley Forest Fire}

\subsection{Initial conditions}

The Swinley forest fire was contained within a 110 hectare region of the Swinley forest (located in southeast England), directly threatening built-up areas. In this example the population within the built-up area is hypothetical and used purely for demonstration purposes. The threatened area consisted of, the Transport Research Laboratory (TRL), consisting of approximately 800 people of mixed working age, a large business estate (BE), consisting of approximately 200 people of mixed working age and predominantly young, a pub, consisting of approximately 200 people of mixed age with a number of elderly and $10 \%$ having some form of minor moving disability, and five residential dwellings (RD), each consisting of a family of two adults and two children. The fire also threatened near-by towns of Bracknell and Crowthorne, the Broadmoor High Security Hospital and the Royal Military Academy Sandhurst. The fire, the largest in Berkshire's history, was attended at one point by 55 appliances from 12 brigades. Fortunately, a road running along the built-up area (B3348) acted as a fire break preventing the fire from spreading to the built-up area. Following this fire considerable analysis was undertaken to determine the impact on the built areas had the wind changed (Gazzard, 2014). One scenario considered a wind change of $90^{\circ}$ to the North 
West. This was modelled using the Prometheus fire spread modelling tool (Smith, 2014). If these conditions had occurred during the fire it would have prompted the evacuation of the nearby built-up area (see Figure 3).

An overview of the area modelled in EXODUS is shown in Figure 3 (total area, 1.58 $\mathrm{km}^{2}$ ). The fire simulations are based on real meteorological data (e.g. fuel maps and ignition locations/times) as recorded on 2 May 2011, however, with slightly different wind conditions (speed and direction). The output shows the simulated spread of the fire for over seven hours using 30-minute intervals. The residents of the indicated buildings are evacuated to the assembly area at the Great Hollands recreation ground, located on the north east side of the built-up area. All the routes leading to the assembly area used by the agents in the simulations are shown in Figure 3.

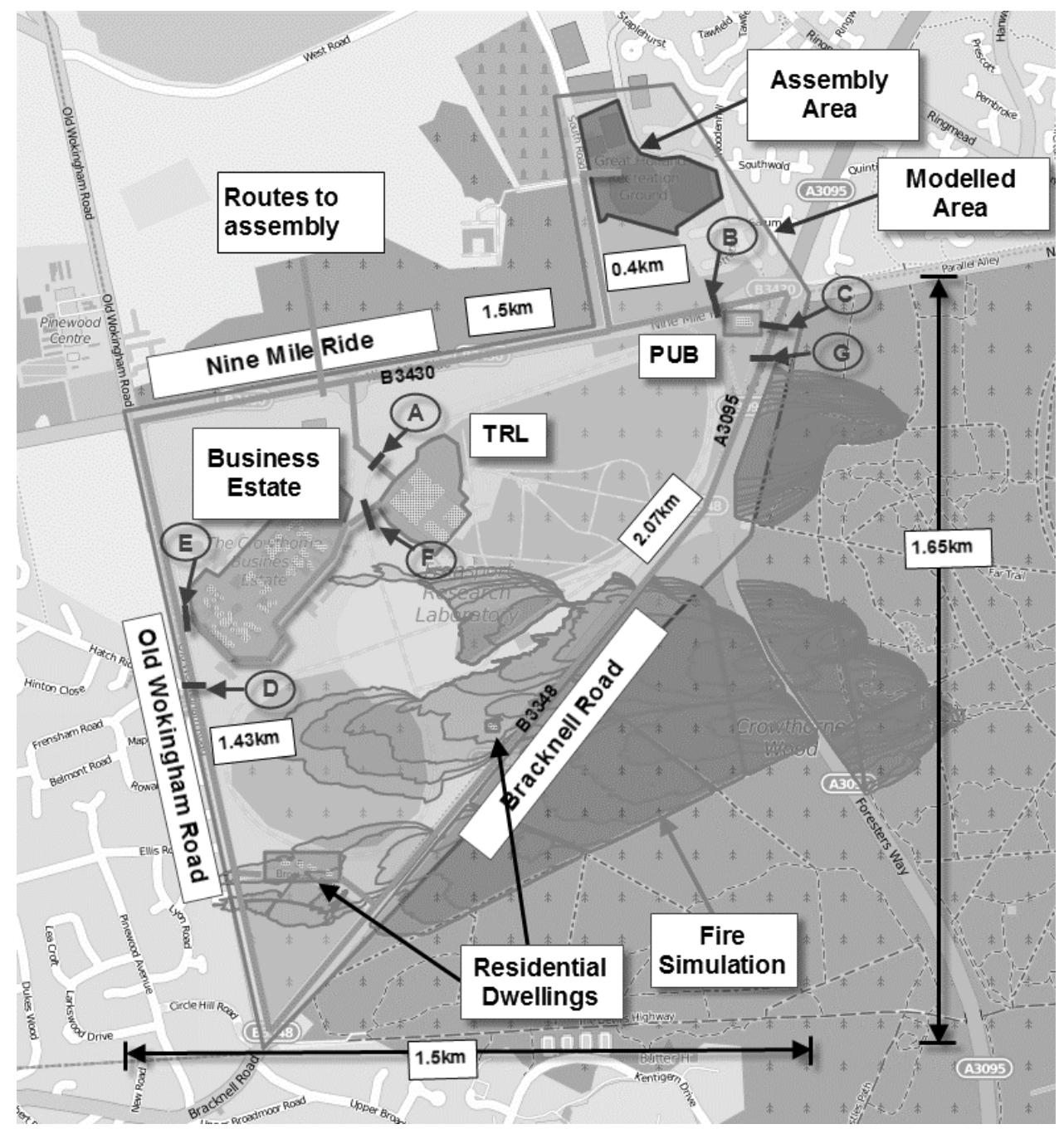

Figure 3: The simulated area in Bracknell which was affected by the wildfire of May 02, 2011 with the simulated hypothetical fire front at $7 \mathrm{hrs}$ after fire initiation (in 30-minute intervals).

\subsection{EVACUATION SCENARIOS}

The evacuation process is undertaken on foot as it is assumed that the roads need to be kept free for use by emergency vehicles and road conditions are considered 
hazardous for vehicles due to reduced visibility resulting from smoke. A total of 1220 agents were distributed in the directly threatened locations (pub, TRL, BE and RD).

During a wildfire affecting large areas it is essential for incident commanders to know which areas to evacuate first (Cova et al., 2005 and Pultar et al., 2009). To do this they need to know when the fire is likely to directly threaten the occupied area, when the fire is likely to threaten proposed evacuation routes, how long is it likely to take to clear the threatened areas and how long it will take for the evacuating population to pass through the at risk evacuation routes. Key locations on the evacuation routes, labelled A to $\mathrm{G}$, are depicted in Figure 3. These represent 'critical locations' which the evacuating population must pass to be considered safe from the approaching fire. These locations were determined by analysing both the fire progression within the fire simulation and the movement of the population within the evacuation simulation. However, rather than the fire front we make use of the hazard front. The hazard front is the region ahead of the fire front that is considered to be untenable. At this point the smoke concentration, visibility and temperature are considered untenable. Ideally, the forest fire model should provide information relating not only to the location of the fire front, but also the position, optical density and composition of the smoke front hence enabling the identification of the hazard front.

Unfortunately, current forest fire models, including Prometheus, do not have this capability and so a $250 \mathrm{~m}$ region ahead of the fire front is assumed to mark the hazardous extent of the fire smoke, here called the hazard front. Thus by knowing the location of the fire front at any point in time (as determined by the fire model), the location of the hazard front, ahead of the fire front, can be determined. Where the hazard front crosses an evacuation route a critical region is identified (see Figure 4). For the evacuation route to be considered safe, the last of the agents using that route must have passed through the critical region and hence be beyond a critical location defining the boundary of the critical region before the hazard front reaches the critical location. The safety margin associated with the compromised route is the difference in time between the time for the predicted hazard front to reach the critical location and the predicted time for the last person to pass through the critical location.

This concept is demonstrated in Figure 4. Here the hazard front crosses the evacuation route at time $t 6$. The location of the hazard front at this time is identified by $L_{t 6}^{1}$ and $L_{t 6}^{2}$ (critical locations) with the critical region being defined as the region on the evacuation route between these critical locations (in this example, $L_{t 6}^{1}<$ critical region $<L_{t 6}^{2}$ ). The last person in the population moving along the evacuation route has location at time $t i$ defined by $L_{t i}^{P}$. Thus for the population to be considered safe, the last person must be beyond the critical region defined by the trailing critical location in the direction of travel and so in this example $L_{t 6}^{P}>L_{t 6}^{2}$. The safety margin is then defined as the difference between the time at which the hazard front is at the critical location, in this example given by $L_{t 6}^{2}(t 6)$, and the time at which the last person was at the critical location, in this example given by $(t 4)$, i.e. $t 6-t 4$, where $t 6$ is determined from the fire simulation and $t 4$ is determined from the evacuation simulation.

As the fire progresses, the hazard front may follow the evacuating population creating a sequence of critical locations and associated safety margins for a given portion of evacuation route. The safety margin for the population on the affected route is then 
taken as the minimum of the sequence of safety margins and the associated critical location is identified. Ideally, this sequence would be determined automatically by the coupled fire and evacuation simulation environment which would then determine the minimum safety margin and associated key critical location. However, in the work presented here the most critical locations for each route and each population (generating the minimum safety margins) are manually estimated by viewing both the fire and evacuation simulation. Thus the reported safety margins can only be considered approximate.

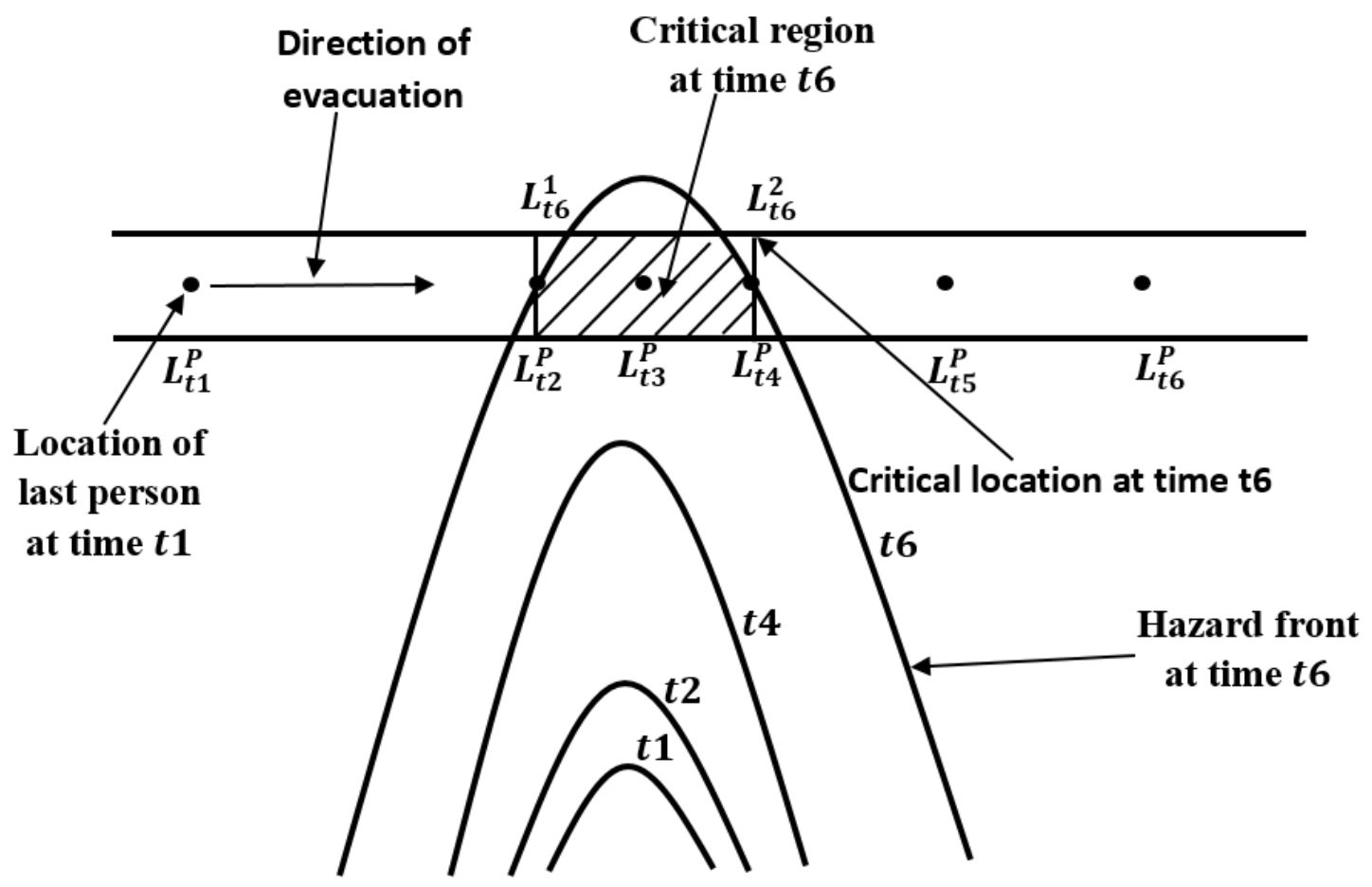

Figure 4: Defining critical region on an evacuation route

Four scenarios are investigated; they consist of a base case in which it is assumed that all evacuation routes are available and three other cases in which various evacuation routes are considered non-tenable. Each case assumes the same population composition and distribution and the same fire conditions. An overview of the four scenarios is provided in Table 1. Within each figure in the table, the arrows indicate the direction of travel of the agents from the buildings. The dashed lines with a cross denote loss of routes.

Table 1: Overview of evacuation scenarios.

\begin{tabular}{|l|c|l|}
\hline Scenario & Diagram & \multicolumn{1}{c|}{ Description } \\
\hline 1 & & $\begin{array}{l}\text { Base case scenario assuming that all routes are } \\
\text { available. Hence all agents take the shortest route } \\
\text { to the assembly location. The critical locations A } \\
\text { (TRL), B (Pub), C, G (RD) and E (BE) represent } \\
\text { the locations that each identified group of agents } \\
\text { must reach prior to the arrival of the hazard front. }\end{array}$ \\
\hline
\end{tabular}




\begin{tabular}{|c|c|c|}
\hline 2 & & $\begin{array}{l}\text { Assumes the path out of TRL connecting to the } \\
\text { Nine Mile Road (B3430) is closed/unusable due } \\
\text { to use by emergency vehicles. The agents in TRL } \\
\text { are thus forced to take a longer route through the } \\
\text { BE. The critical location for the agents in TRL is } \\
\text { now F instead of A. }\end{array}$ \\
\hline 3 & & $\begin{array}{l}\text { Assumes that a part of the Bracknell road is } \\
\text { unsafe to use forcing the agents in the residential } \\
\text { dwellings to take a slightly longer route via Old } \\
\text { Wokingham Road - Nine Mile Road to the } \\
\text { shelter location. In this case, the critical location } \\
\text { for the agents in the RD is D instead of C. This } \\
\text { part of the Bracknell road is the first route to be } \\
\text { affected by the fire and hence this is an important } \\
\text { scenario. }\end{array}$ \\
\hline 4 & & $\begin{array}{l}\text { This scenario assumes that the route losses from } \\
\text { Scenarios } 2 \text { and } 3 \text { are merged in this scenario. }\end{array}$ \\
\hline
\end{tabular}

All the scenarios have the same initial conditions in terms of the number, nature, and distribution of agents, their response times and the location of the assembly area which is at the Great Hollands Recreation centre located in the north east. The four scenarios differ in terms of the routes taken by the evacuating population. The routes utilised by the agents in the four scenarios and the critical locations for the various establishments are shown in Table 1. The critical locations A to $\mathrm{G}$ differ for each scenario depending upon the routes taken by the agents. For example, in Scenario 1, the agents located within the TRL building are considered to be safe after clearing critical location A. However, in Scenario 2 a different path is adopted by the TRL agents and so the critical location for these agents is now location $\mathrm{F}$.

Within each scenario the agent response times were specified as follows:

- Pub: 30 - $60 \mathrm{~s}$, proprietor alerted by phone call from police at $\mathrm{t}=0 \mathrm{~s}$.

- TRL: 60 - $120 \mathrm{~s}$, building managers alerted by phone call from police at $\mathrm{t}=0$ S.

- BE: 60 - $120 \mathrm{~s}$, building managers alerted by phone call from police at $\mathrm{t}=0 \mathrm{~s}$.

- RD: 10 to 16 min, alerted by the police door knock. Each dwelling is visited in turn by a police patrol that informs residents to evacuate. The police reach the first house at $\mathrm{t}=300 \mathrm{~s}$. The second house is visited $60 \mathrm{~s}$ later and so on. Each household is arbitrarily assigned a 5 min response time once alerted. It is assumed that the residential dwellings have been pre-warned of the possible need to evacuate and so have prepared for the evacuation.

Occupant response times for these types of situations are not known and so the values used in these simulations are intended for demonstration purposes. In reality it is likely 
that people would have much longer response times, especially for RD. Furthermore, it is possible that some of the occupants of the RD may chose not to evacuate but to defend their properties. In addition, the start of the evacuation $(t=0 \mathrm{~s})$ occurs at the time of fire initiation. This is unlikely to be the case in reality as it will take some time for the fire to grow to a size that can be detected and then for the fire to develop to the point that it may be considered a threat. However for simplicity in this demonstration the evacuation process is considered to start at the start of the fire. The walking speeds of the agents in the simulations is randomly allocated between $0.85 \mathrm{~m} / \mathrm{s}$ to $1.1 \mathrm{~m} / \mathrm{s}$. Note that these speeds are less than the normal defaults used in buildingEXODUS which are usually between $1.2 \mathrm{~m} / \mathrm{s}$ and $1.5 \mathrm{~m} / \mathrm{s}$. In reality the walking speed of people would depend on a range of factors such as age, gender, disability, nature of group, fatigue, etc. These simplifications should be taken into consideration when assessing the results presented.

\section{$5 \quad$ Results and Discussion}

The evacuation simulation results for the four scenarios are presented in this section. Each scenario was run ten times and the values referred to in this section represent the average of these ten simulations. The arrival times and safety margin graphs for each scenario are presented and discussed in this section. The arrival times graph shows the times at which agents arrive at the assembly location. The safety margins graph shows the time for the fire front to be within $250 \mathrm{~m}$ of a critical location, the time for the last person to pass through the critical region and the safety margin, which is the difference between these two times. It is noted that all the simulations are performed using an Intel Xeon E5-1620 computer with a clock speed of $3.6 \mathrm{GHz}$ and $64 \mathrm{~GB}$ of RAM.

\subsection{Scenario 1}

\subsubsection{Arrival times}

The arrival times of the entire population at the assembly location is shown in Figure 5. The agents in the pub are closest to the assembly location, have a short response time, and hence are the first to arrive at $13 \mathrm{~min}$. All 200 agents from the pub reach the assembly location within 19 min from the start of the simulation. After the pub, the agents from TRL are the nearest and start to arrive in the assembly area at around 22 min. The 800 agents from TRL assemble within $35 \mathrm{~min}$. The first agents from the BE arrive at around the same time as the last agents from TRL and start assembling at 35 $\min$. The 200 agents from the BE assemble by 52 min after the start of simulation. The agents from the RD are the last to arrive as they have much higher response times and distance to travel compared to the rest of the population. The 20 agents in the RD and hence the entire population assembles in $1 \mathrm{hr} 12 \mathrm{~min} 45 \mathrm{~s}$ (72.75 min). The EXODUS engine provided the simulation results in 3 min $22 \mathrm{~s}$. It was thus possible to run the simulation 21.4 times faster than real time. 


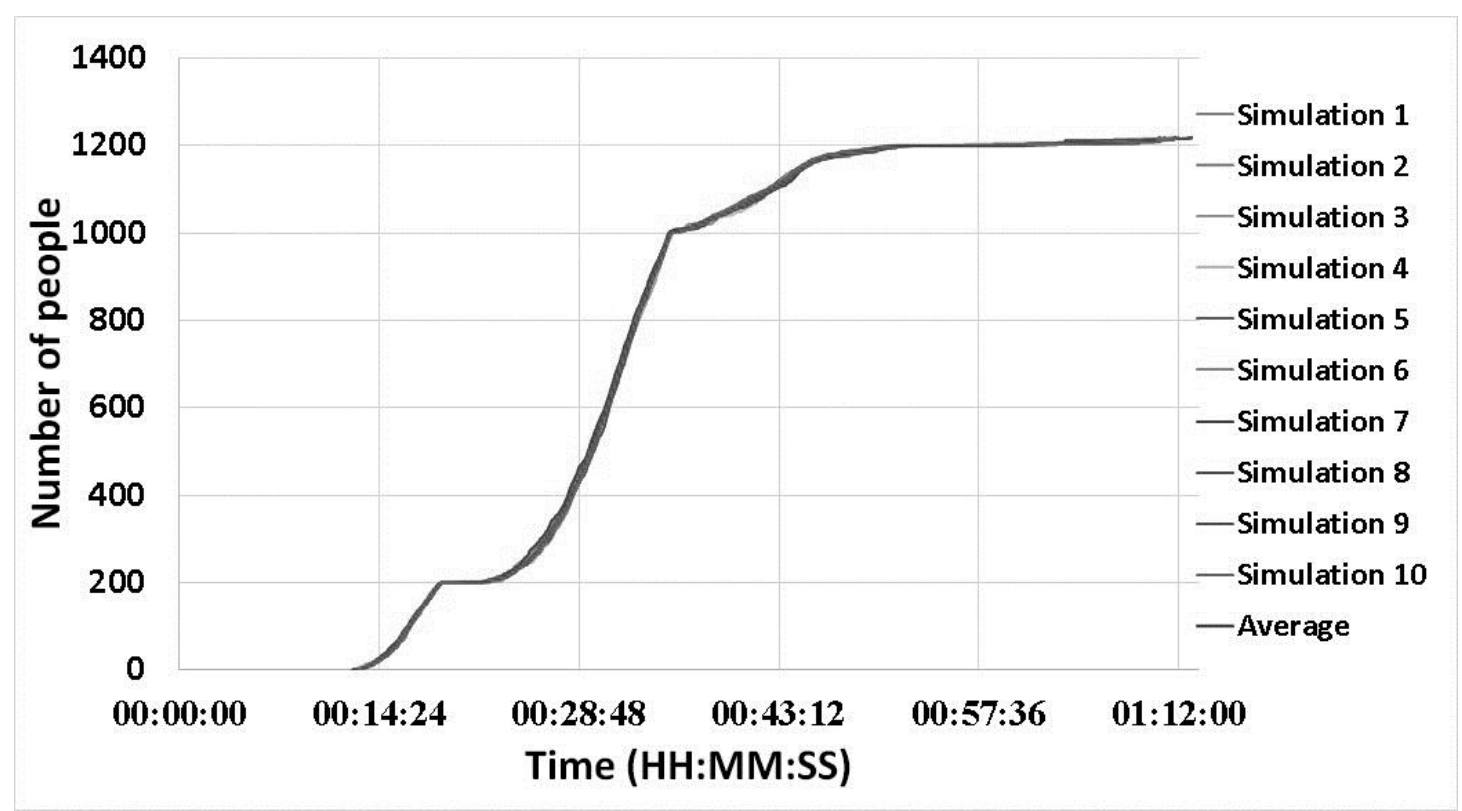

Figure 5: Arrival times at the assembly location for Scenario 1

\subsubsection{Safety margins}

The time for the agents to clear the relevant critical locations, the time for non-tenable conditions to develop at the critical locations (i.e. the time for the hazard front to reach the critical location) and the safety margin (i.e. the difference between the time for nontenable conditions to develop at the critical location and time for the agents to clear the critical locations) for Scenario 1 is shown in Figure 6. The agents in the pub are quick to clear critical location B, doing so in $4 \mathrm{~min} 28 \mathrm{~s}$. The fire approaches critical location $\mathrm{B}$ at $1 \mathrm{hr} 31 \mathrm{~min}$. The agents in the pub therefore have a safety margin of $1 \mathrm{hr} 26 \mathrm{~min}$ 30s. The safety margin is intended to compensate for a number of uncertainties within the evacuation modelling including for example, delays in notifying the population, delays in population response, slower walking speeds, etc. For example, the pub residents could be warned of the need to start their evacuation up to $1 \mathrm{hr} 26 \mathrm{~min} 30 \mathrm{~s}$ later than assumed within the simulation and they would still be able to reach safety. The agents from TRL and the BE have the largest safety margins (more than $4 \mathrm{hr}$ ) as they are quick to clear their relevant critical location and the fire is predicted to take a longer time to affect their routes. In this scenario, the agents in the RD have the smallest safety margin of just $12 \mathrm{~min}$ which is primarily due to them requiring a relatively long time (48 $\mathrm{min}$ ) to clear the relevant critical location $\mathrm{G}$. The hazard front is also quick to approach this critical location at $1 \mathrm{hr}$. At the other critical location $\mathrm{C}$, located further along the evacuation route, the agents from the RD have a safety margin of $37 \mathrm{~min} 6 \mathrm{~s}$ which is mainly due to the hazard front taking a longer time to reach this location at $1 \mathrm{hr}$ and $31 \mathrm{~min}$. Clearly the agents from the RD have to clear both critical locations ( $\mathrm{C}$ and $\mathrm{G})$, but the critical location with the smallest safety margin is critical location $\mathrm{G}$ and so this defines the critical safety margin. Though the hazard front also approaches critical location B in approximately the same period of time, the agents in the pub clear this critical location very quickly (less than $5 \mathrm{~min}$ ) and hence this is not considered a great threat for the pub occupants. If the people in the RD are to take the Bracknell road to reach the assembly location it is essential that they are warned as quickly as possible. Thus the police doing the door knock must not lose time in road congestion getting to the RD, once they arrive they must spend very little time explaining the situation and 
the residents must then respond to the warning quickly as they only have a safely margin of $12 \mathrm{~min}$. Given how tight the safety margins are for the RD in this scenario, the evacuation strategy adopted in this scenario is not considered viable.

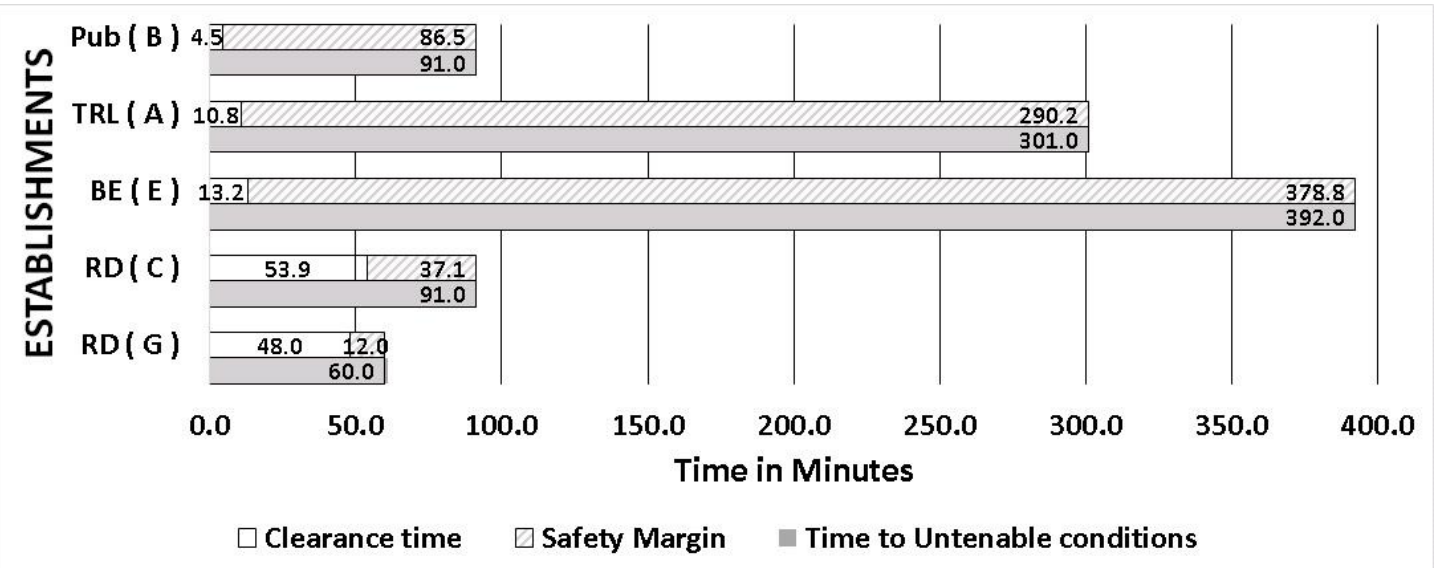

Figure 6: Evacuation and fire timelines for the different establishments in Scenario 1

\subsection{Scenario 2}

\subsubsection{Arrival times}

Similar to Scenario 1, the agents in the pub assemble within 19 min (see Figure 7) as there is no change to their evacuation route. In Scenario 2 agents from TRL are forced to take a longer path via the BE as shown in Table 1. Thus in this scenario the agents in TRL have a longer route to the assembly location compared to the agents from BE. The agents from the BE are thus the next to start arriving at the assembly location at 34 $\min$. Due to a distribution of walk speeds between $0.85 \mathrm{~m} / \mathrm{s}$ and $1.1 \mathrm{~m} / \mathrm{s}$ the fastest agents from TRL assemble before the slowest agents from BE. The agents from BE and TRL assemble within $1 \mathrm{hr} 7 \mathrm{~min}$. The last agents to arrive are again the agents from the RD. The first agents from the RD begin to arrive at around the same time as the last agents from TRL. The last of the agents from the RD and hence the overall assembly time for this scenario is $1 \mathrm{hr} 11 \mathrm{~min}$ which is very similar to Scenario 1 . The total evacuation times have not changed significantly in these two scenarios as the agents from the RD are always the last to arrive and their route has not changed. However, 800 agents from TRL take a longer route $(3 \mathrm{~km})$ to the assembly location in Scenario 2 which is twice the distance of the route taken in Scenario $1(1.5 \mathrm{~km})$. Furthermore, the average level of congestion experienced by the agents from TRL (measured by the average Cumulative Wait Time or CWT) is $84 \%$ greater than the level of congestion they experienced in Scenario 2. The average time a TRL agent spent in reaching the assembly location (measured by the Personal Elapsed Time or PET) has increased by 93\% in Scenario 2. This indicates that even though the overall evacuation times are similar in Scenarios 1 and 2 the two scenarios differ significantly in terms of the evacuation dynamics experienced by the various sub-populations. The EXODUS engine provided the simulation results in $3 \mathrm{~min} 38 \mathrm{~s}$. It was thus possible to run the simulation 19.5 times faster than real time. 


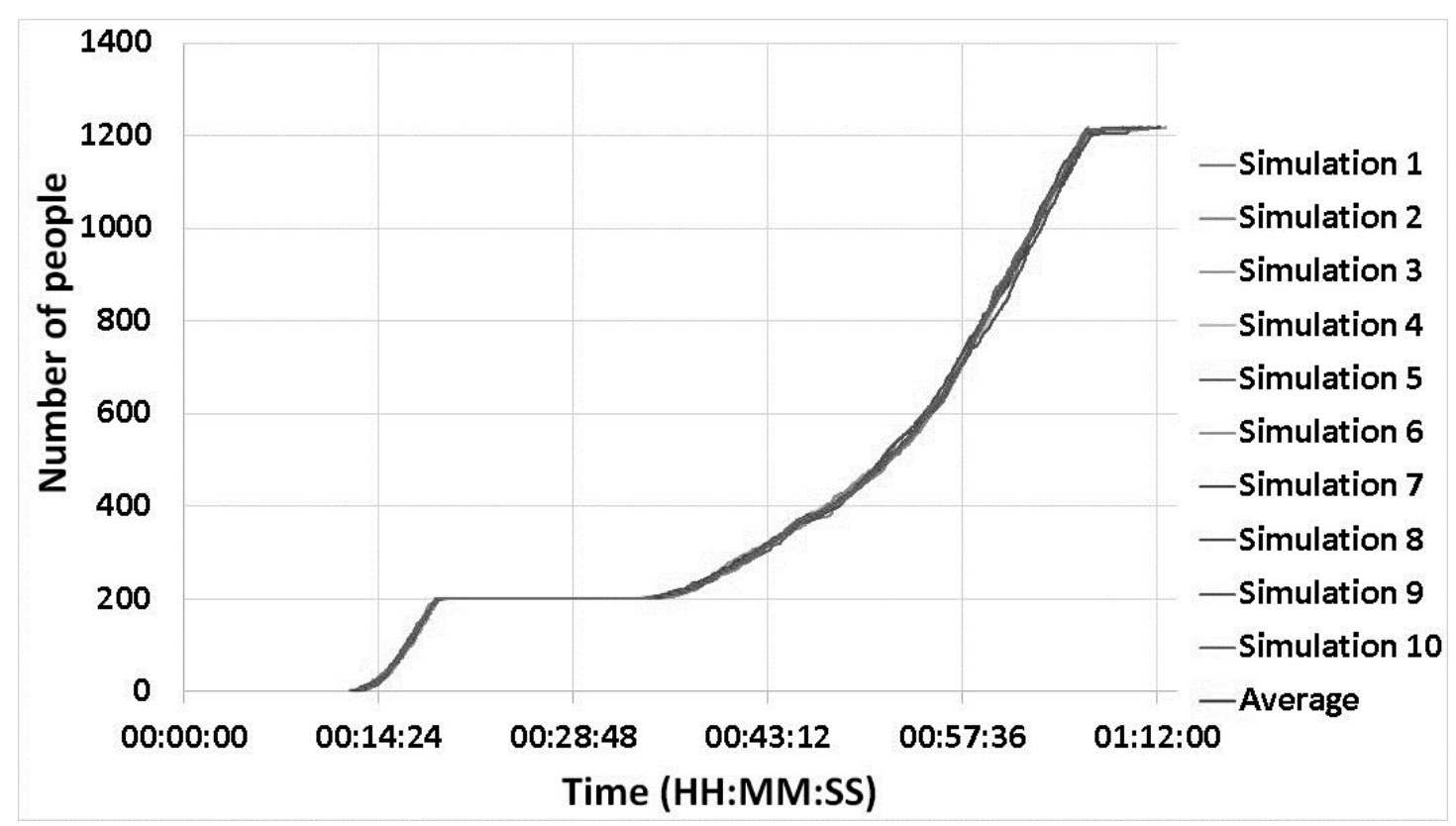

Figure 7: Arrival times at the assembly location for Scenario 2

\subsubsection{Safety margins}

The safety margins for the agents in the various buildings in Scenario 2 are shown in Figure 8. The agents in the pub and the RD have similar safety margins as in Scenario 1. The agents in TRL now have two critical locations to clear - critical locations F and E. Clearing the first critical location F indicates that they have cleared the TRL site and hence are safe in the event of the fire approaching the TRL site. Critical location F is closer to the approaching hazard front than critical location $\mathrm{A}$, thus the time for the fire hazards to approach critical location $\mathrm{F}$ is shorter than the time for the fire hazards to approach critical location A. This is the main reason for the 29 min decrease in the safety margin available for the agents from TRL in Scenario 2 compared to Scenario 1. The TRL agents thus have a 4 hour 21 min 18 s safety margin at critical location A. In this scenario the TRL agents have to take a similar path to the assembly location as the agents from BE. Hence they need to also clear the critical location $\mathrm{E}$ along with the BE agents. The BE agents are the first to clear the location $\mathrm{E}$ at $13 \mathrm{~min} 18 \mathrm{~s}$ giving them a safety margin of $6 \mathrm{hr} 18 \mathrm{~min} 42 \mathrm{~s}$. The first of the TRL agents to arrive at location E do so at 14 min which is approximately $1 \mathrm{~min}$ after the last of the BE agents have left the region. Thus there is no interaction between the agents from the BE and TRL at location E. The agents from TRL clear location $\mathrm{E}$ at $26 \mathrm{~min} 36 \mathrm{~s}$ giving them a safety margin of $6 \mathrm{hr} 5 \mathrm{~min} 24 \mathrm{~s}$. Since the TRL agents have to clear two critical locations A and E the lower safety margin $4 \mathrm{hr} 21 \mathrm{~min} 18 \mathrm{~s}$ is considered as their critical safety margin in this scenario. 


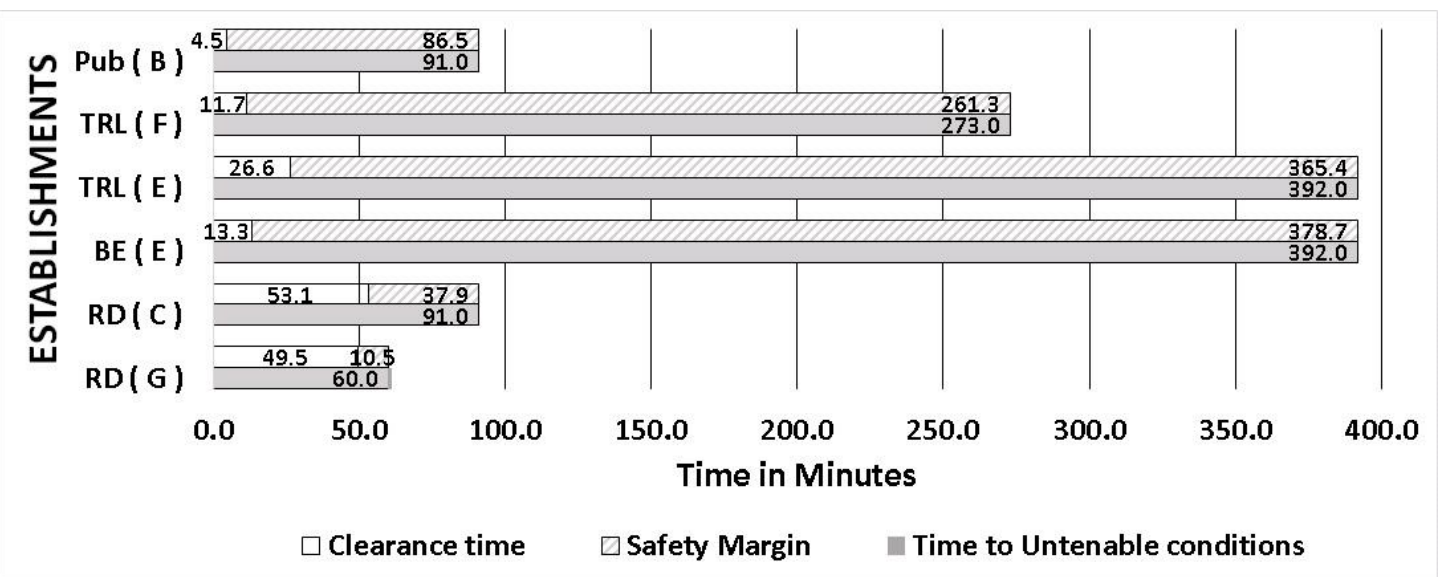

Figure 8: Evacuation and fire timelines for the different establishments in Scenario 2

\subsection{Scenario 3}

\subsubsection{Arrival times}

The difference between Scenario 1 and Scenario 3 is the loss of a part of Bracknell Road forcing the agents in the RD to take a slightly longer route. There are 20 agents from the RD who are the last to reach the assembly location. Therefore, the arrival times graph for Scenario 3 (see Figure 9) is similar to that of Scenario 1 (see Figure 5) except for a small difference towards the end of the evacuation which is a result of the RD agents taking a slightly longer time to reach the assembly region. The assembly time for the agents from the RD and hence the overall assembly time for the entire population in this scenario is $1 \mathrm{hr} 26 \mathrm{~min}$ which is greater than Scenario 1 by $15 \mathrm{~min}$. The overall assembly time for this scenario is $1 \mathrm{hr} 26 \mathrm{~min} 14 \mathrm{~s}$. The EXODUS engine provided the simulation results in $3 \mathrm{~min} 55 \mathrm{~s}$. It was thus possible to run the simulation 22 times faster than real time.

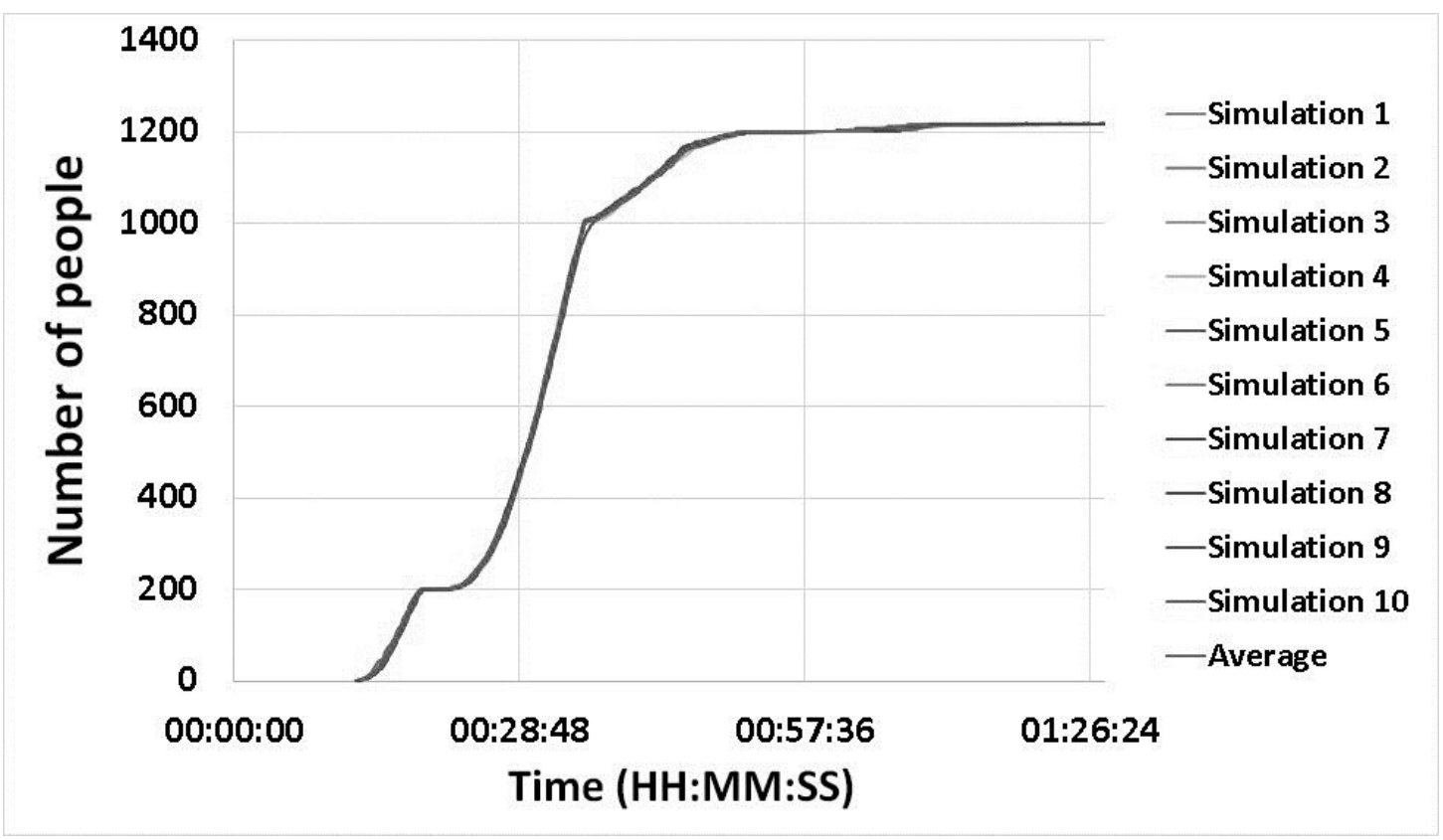

Figure 9: Arrival times at the assembly location for Scenario 3 


\subsubsection{Safety margins}

The safety margins for the agents in the various buildings in Scenario 3 are shown in Figure 10. Although Scenario 3 produces the longest overall evacuation time of the three scenarios, the agents in the RD have a higher safety margin, $2 \mathrm{hr} 45 \mathrm{~min}$ compared to only $37 \mathrm{~min}$ in Scenarios 1 and 2. This is because the critical location for the RD on this alternative route, location $\mathrm{D}$, is further away from the approaching fire front than critical location $\mathrm{C}$. The agents in the RD are also slightly closer to critical location $\mathrm{D}$ than critical location $\mathrm{C}$ and thus pass critical location $\mathrm{D}$ sooner than they would have passed critical location C. The safety margins for TRL, BE and the Pub remain the same as those for Scenario 1.

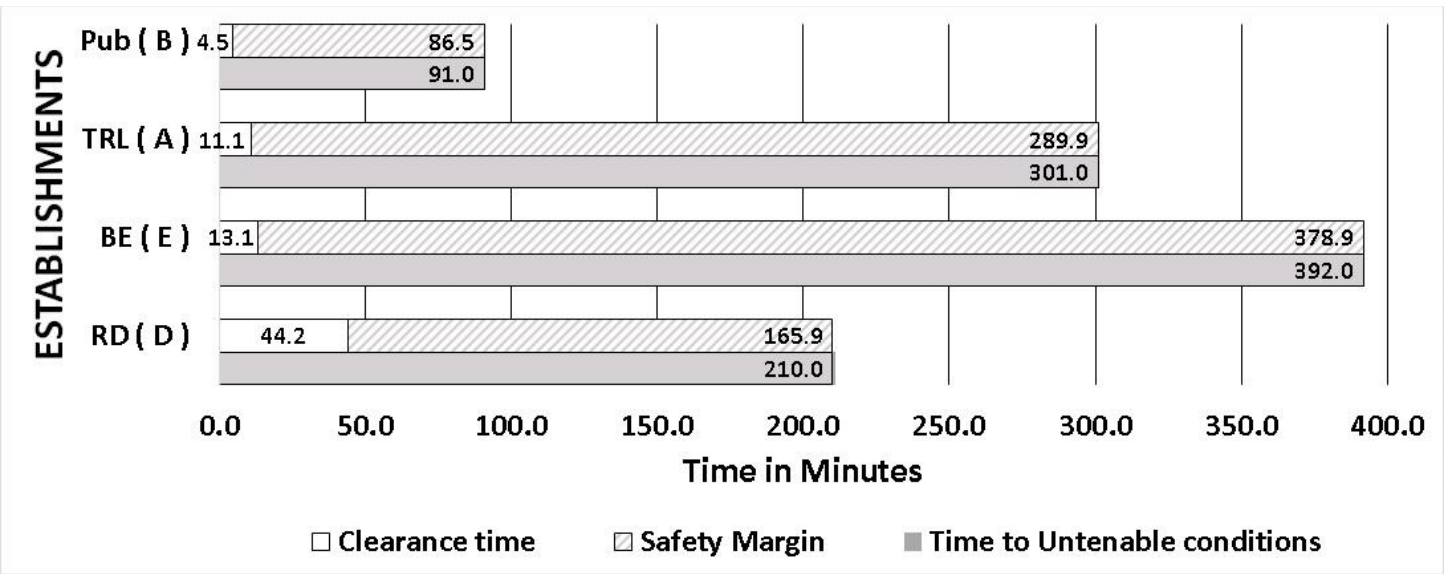

Figure 10: Evacuation and fire timelines for the different establishments in Scenario 3

\subsection{Scenario 4}

\subsubsection{Arrival times}

The arrival times of the agents from the various buildings at the assembly location are shown in Figure 11. The overall shape of the arrival curve is similar to Scenario 2 as in both these scenarios the TRL agents take a slightly longer route to the assembly station. However, the total assembly time in this scenario is similar to that in Scenario 3 as the last agents to assemble in both Scenarios 3 and 4 are the agents from the RD and in both scenarios these agents are forced to take a slightly longer route as part of the Bracknell Road is assumed to be unusable. The overall assembly time for Scenario 4 is $1 \mathrm{hr} 24 \mathrm{~min} 38 \mathrm{~s}$. The EXODUS engine provided the simulation results in 4 min $12 \mathrm{~s}$. It was thus possible to run the simulation 20.2 times faster than real time. 


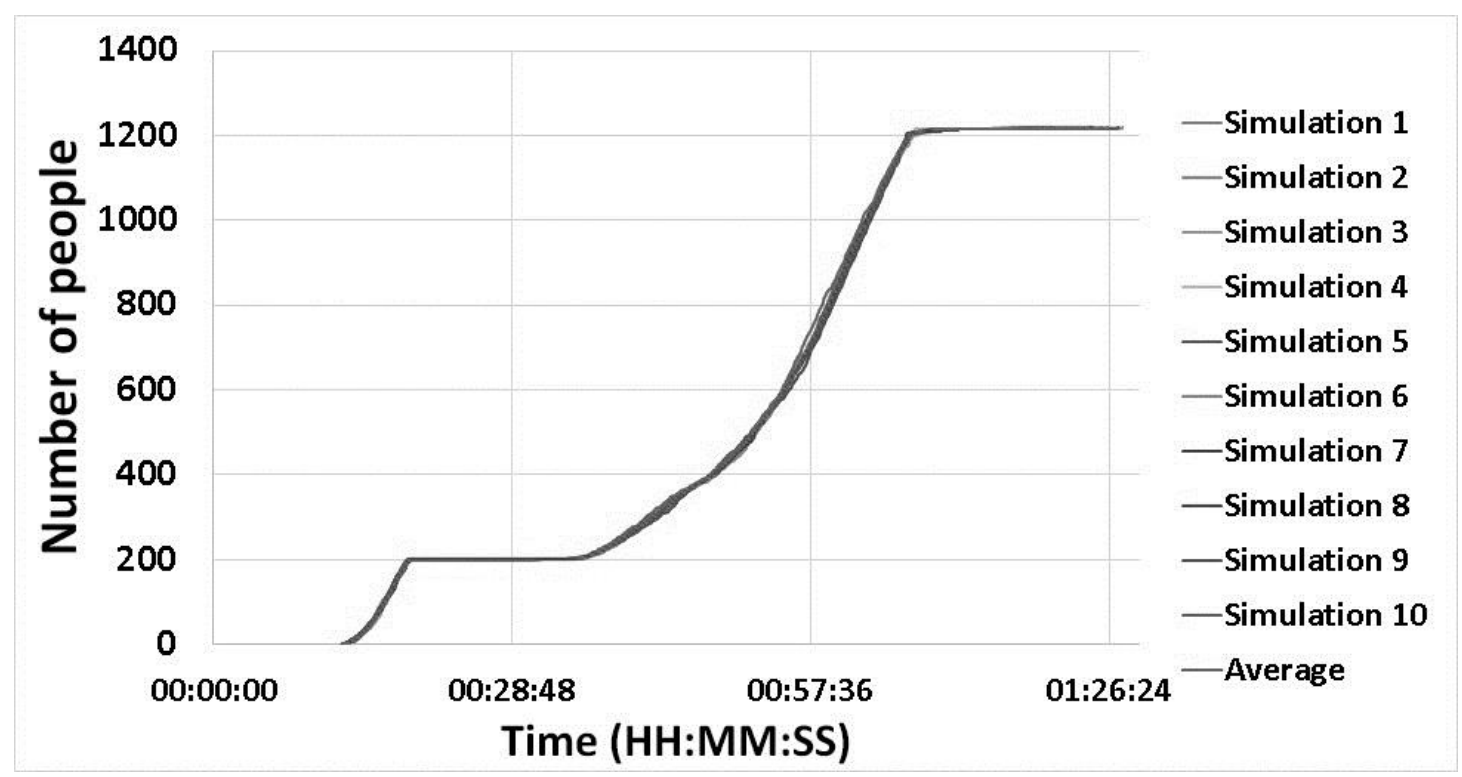

Figure 11: Arrival times at the assembly location for Scenario 4

\subsubsection{Safety Margins}

The safety margins for the agents in the various buildings in Scenario 4 are shown in Figure 12. The safety margin available for the agents in the pub is almost identical across all four scenarios as their path has not been altered. The safety margin available for the TRL agents is the same as that in Scenario 2 as in these two scenarios the agents from TRL take the same route. Similar to Scenario 2 the TRL agents have a second critical location, location $\mathrm{E}$ to clear along with the agents from the BE. The BE agents clear this location first at 13 min $6 \mathrm{~s}$ and have a safety margin of $6 \mathrm{hr} 18 \mathrm{~min} 54 \mathrm{~s}$. There is a gap of approximately $1 \mathrm{~min}$ between the times for the last $\mathrm{BE}$ to clear location $\mathrm{E}$ and the time for the first TRL agent to reach it. The TRL agents clear location E at 26 $\min 42 \mathrm{~s}$ giving them a safety margin of $6 \mathrm{hr} 5 \mathrm{~min} 18 \mathrm{~s}$. The lower of the two safety margins for the agents from TRL, which is $4 \mathrm{hr} 21 \mathrm{~min} 18 \mathrm{~s}$ at location $\mathrm{F}$, is hence more critical in this scenario. The safety margin for the agents from the RD is approximately the same as that for Scenario 3 as in these two scenarios the agents from the RD utilise the same path.

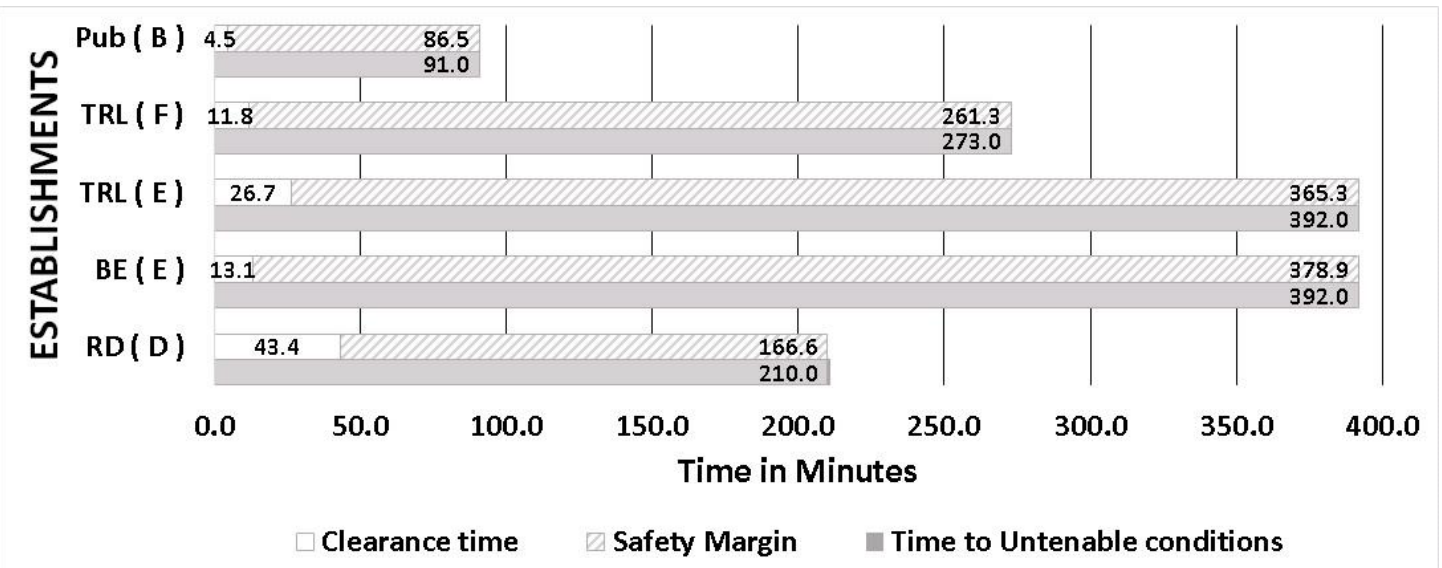

Figure 12: Evacuation and fire timelines for the different establishments in Scenario 4 


\subsection{Comparison of the four scenarios}

\subsubsection{Assembly times and distance travelled}

The assembly times and distance travelled by the agents from the different locations in each scenario is shown in Table 2. The agents from the pub are always the first to assemble. The RD agents are always the last to assemble in all scenarios and thus determine the overall assembly times for the entire population. A graph of the times at which the agents arrive at the assembly locations for all the four scenarios is shown in Figure 13.

The evacuation dynamics for Scenarios 1 and 3 are quite similar and the evacuation dynamics of Scenarios 2 and 4 are quite similar, but both pairs exhibit quite different evacuation dynamics to each other. The evacuation dynamics in Scenarios 1 and 3 are similar as the only difference between the two scenarios is that the agents from the RD take a slightly longer route in Scenario $3(2.7 \mathrm{~km}$ versus $3.0 \mathrm{~km})$ compared to Scenario 1. In these scenarios we note that there is a rapid build-up of people in the assembly area after approximately $21 \mathrm{~min}$. This is due to the arrival of people from TRL. While the evacuation dynamics in these two scenarios are broadly similar, there is a large difference (14 min or 20\%) in the overall assembly times between these two scenarios. This is a result of the agents from the RD travelling an additional $0.3 \mathrm{~km}$ to reach the assembly location in Scenario 3.

The evacuation dynamics in Scenarios 2 and 4 are quite similar as again, the only difference between these two scenarios is that the agents from the RD take a slightly longer route in Scenario $4(2.7 \mathrm{~km}$ versus $3.0 \mathrm{~km})$ compared to Scenario 2. In these scenarios we note that there is a slower build-up of people in the assembly area compared to that in Scenarios 1 and 3. This difference is due to the occupants from TRL taking a longer route to the assembly location $(3.0 \mathrm{~km}$ versus $1.5 \mathrm{~km})$ in Scenarios 2 and 4 compared to Scenarios 1 and 2. This has a significant impact on the development of the arrival times. Indeed, as noted in Figure 3, after the arrival of the last occupants from the pub into the assembly area there is a period of about $16 \mathrm{~min}$ when no further agents arrive in the assembly location. While Scenarios 2 and 4 have broadly similar evacuation dynamics, there is again a large difference (14 min or 20\%) in overall assembly times between these two scenarios. As with Scenarios 1 and 3, this is due to the slightly longer evacuation route taken by the occupants of the RD in Scenario 4 compared to Scenario 2.

The overall assembly times in Scenarios 1 and 2 are similar as are those in Scenarios 3 and 4. This is because the final assembly times are determined by the arrival times of the RD occupants. In Scenarios 1 and 2 the occupants of the RD follow the same route (most direct route) while in Scenarios 3 and 4 they follow the slightly longer route. Hence the overall assembly times for Scenarios 1 and 2 are slightly shorter $(71 \mathrm{~min}$ or $16 \%$ ) compared to those for Scenarios 3 and 4 (85 min).

In all four scenarios the agents in the pub start arriving at the assembly location $13 \mathrm{~min}$ after the call to evacuate. All 200 agents from the pub assemble after $20 \mathrm{~min}$. The agents in the pub take the same routes $(0.8 \mathrm{~km})$, have the same response times and do not share their escape route with other agents for all the four scenarios. This explains why they exhibit a uniform behaviour in all four scenarios. In Scenarios 1 and 3 the agents from 
TRL take the next shortest route $(1.5 \mathrm{~km})$ to the assembly location. Hence in these scenarios they arrive next and start to arrive at the assembly location after around 22 $\min$. There is a $3 \mathrm{~min}$ gap between the last person arriving from the pub and the first person arriving from TRL in Scenarios 1 and 3. The 800 agents from TRL travel 1.5 $\mathrm{km}$ and assemble within $36 \mathrm{~min}$. The first agents from the BE arrive at the assembly location about the same time as the last agents from TRL. The 200 agents from the BE travel $2.3 \mathrm{~km}$ and assemble within $52 \mathrm{~min}$. The agents in the RD are the next to arrive and start to assemble after $61 \mathrm{~min}$ in Scenario 1 and $64 \mathrm{~min}$ in Scenario 3. This is because the agents from the RD take a slightly longer route in Scenario 3 compared to Scenario $1-0.3 \mathrm{~km}$ longer. All the agents from the RD are assembled after $1 \mathrm{hr} 11 \mathrm{~min}$ in Scenario 1 and $1 \mathrm{hr} 26 \mathrm{~min}$ in Scenario 3.

Table 3: Times to assemble and distance travelled by the agents in various establishments in the four scenarios

\begin{tabular}{|c|c|c|c|c|c|c|c|c|}
\hline \multirow{2}{*}{ Scenarios } & \multicolumn{4}{|c|}{ Assembly times (HH:MM:SS) } & \multicolumn{4}{c|}{ Distance travelled (km) } \\
\cline { 2 - 9 } & Pub & TRL & BE & RD/ALL & Pub & TRL & BE & RD \\
\hline $\mathbf{1}$ & $00: 18: 38$ & $00: 35: 26$ & $00: 51: 36$ & $01: 11: 32$ & 0.8 & 1.5 & 2.3 & 2.7 \\
\hline $\mathbf{2}$ & $00: 18: 37$ & $01: 07: 05$ & $00: 52: 09$ & $01: 10: 26$ & 0.8 & 3.0 & 2.3 & 2.7 \\
\hline $\mathbf{3}$ & $00: 18: 42$ & $00: 35: 35$ & $00: 51: 16$ & $01: 26: 01$ & 0.8 & 1.5 & 2.3 & 3.0 \\
\hline $\mathbf{4}$ & $00: 18: 40$ & $01: 07: 25$ & $00: 52: 31$ & $01: 24: 25$ & 0.8 & 3.0 & 2.3 & 3.0 \\
\hline
\end{tabular}

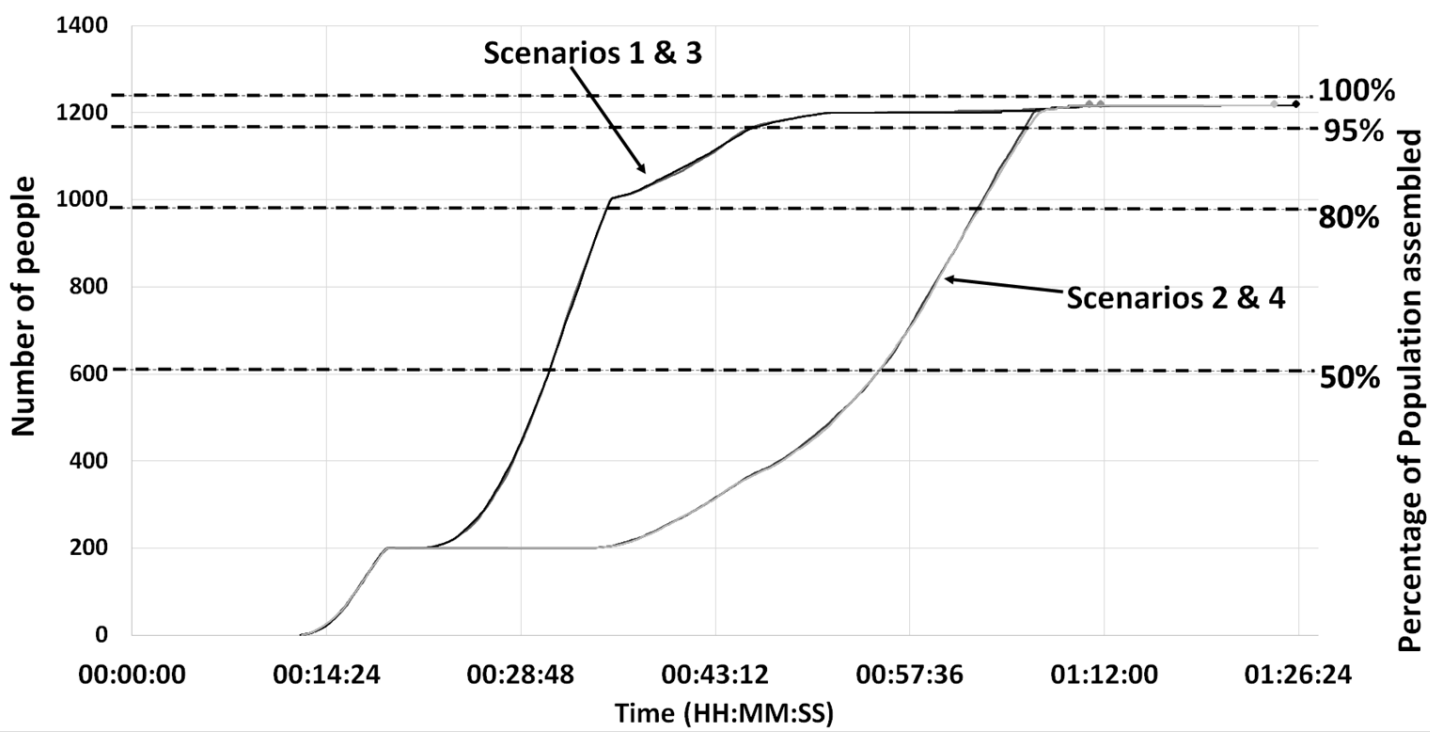

Figure 13: Comparison of the arrival times at the assembly location. The times at which proportions $(50 \%, 80 \%, 95 \%$ and $100 \%)$ of the entire population assemble is denoted by horizontal dashed lines.

\subsubsection{Assembly Performance}

The times at which various proportions $(50 \%, 80 \%, 95 \%$ and $100 \%)$ of the population arrive at the assembly location is provided in Table 4. As already noted there is a rapid build-up of people in the assembly area in Scenarios 1 and 3 compared to Scenarios 2 and 4. This is due to the occupants from TRL taking the direct route to the assembly station. From Table 3 we note that within Scenarios 1 and 3, not only do $50 \%$ of the population arrive at the assembly location in just under $31 \mathrm{~min}$ (compared to just over 
55 min in Scenarios 2 and 4), but $95 \%$ of the total population have assembled in a shorter time than the time taken for $50 \%$ of the population to assemble in Scenarios 2 and 4. Thus in Scenarios 1 and 3 it is essential that the assembly locations are staffed and ready to handle the arrival of large numbers of people in a relatively short period of time $-30 \mathrm{~min}$ from the start of the evacuation process.

Furthermore, in Scenarios 1 and 3 the arrival time curve has a long tail, the last 5\% of the population requiring between $26 \mathrm{~min}$ (in Scenario 1) and $41 \mathrm{~min}$ (in Scenario 3). This is equivalent to the time required for the first $50 \%$ to arrive in the assembly in the assembly location. Indeed, in Scenario 3, the last 5\% of the population require almost $50 \%$ of the total assembly time.

Table 4: Times at which proportion of entire population assembled

\begin{tabular}{|c|c|c|c|c|}
\hline $\begin{array}{c}\text { Proportion } \\
\text { Assembled }\end{array}$ & $\begin{array}{c}\mathbf{5 0 \%} \\
\mathbf{( 6 1 0 )}\end{array}$ & $\begin{array}{c}\mathbf{8 0 \%} \\
\mathbf{( 9 7 6 )}\end{array}$ & $\begin{array}{c}\mathbf{9 5 \%} \\
\mathbf{( 1 1 5 9 )}\end{array}$ & $\begin{array}{c}\mathbf{1 0 0 \%} \\
\mathbf{( 1 2 2 0})\end{array}$ \\
\hline Scenario 1 & $00: 30: 56$ & $00: 35: 05$ & $00: 45: 19$ & $01: 11: 45$ \\
\hline Scenario 2 & $00: 55: 22$ & $01: 02: 30$ & $01: 05: 58$ & $01: 10: 54$ \\
\hline Scenario 3 & $00: 30: 55$ & $00: 35: 06$ & $00: 45: 29$ & $01: 26: 14$ \\
\hline Scenario 4 & $00: 55: 20$ & $01: 02: 40$ & $01: 06: 11$ & $01: 24: 38$ \\
\hline
\end{tabular}

\subsubsection{Safety Margins}

Presented in Table 5 are the safety margins associated with the various populations in each scenario. The smallest safety margins are $11 \mathrm{~min}$ and $12 \mathrm{~min}$ for the occupants of the RD in Scenarios 1 and 2 respectively and $87 \mathrm{~min}$ for the occupants of the pub in Scenarios 3 and 4 . The longest safety margins are over $360 \mathrm{~min}$ and are associated with the population from the $\mathrm{BE}$ in all four scenarios.

The very short safety margins associated with Scenarios 1 and 2 are due to the occupants from the RD taking the shortest route to the assembly location i.e. along Bracknell Road, which inevitably takes them quite close to the fire start location and directly in the path of fire spread. Given that the start of the evacuation process is associated with the start of the fire, this means that there could only be a maximum of 11 min delay between the start of the fire and the notification of the population in the RD before Scenarios 1 and 2 would become non-viable.

In Scenarios 3 and 4, the RD population take the longest route to the assembly location, i.e. along Old Wokingham Road, which takes them effectively away from the hazard front and hence gives them a much higher safety margin of over $165 \mathrm{~min}$ (associated with clearing critical point $\mathrm{D})$. Although the RD agents travel a longer route $(0.3 \mathrm{~km}$ more) via the Old Wokingham Road, it is the route that offers them maximum safety and is the only viable route given the delay likely between starting the evacuation and detecting the fire. The Pub occupants also have a relatively small safety margin requiring them to start their evacuation within $86 \mathrm{~min}$ of fire initiation, regardless of which scenario is considered. The agents in the other establishments (TRL and BE) 
have more than four hour safety margin in all scenarios and hence can be considered to be quite safe in terms of warning time and time needed to reach safety locations.

Table 5: Critical safety margins (min) and critical locations

\begin{tabular}{|l|c|c|c|c|}
\hline & Pub & TRL & BE & RD \\
\hline Scenario 1 & $87(B)$ & $290(A)$ & $379(E)$ & $12(\mathrm{G})$ \\
\hline Scenario 2 & $87(B)$ & $261(\mathrm{~F})$ & $379(\mathrm{E})$ & $11(\mathrm{G})$ \\
\hline Scenario 3 & $87(\mathrm{~B})$ & $290(\mathrm{~A})$ & $379(\mathrm{E})$ & $166(\mathrm{D})$ \\
\hline Scenario 4 & $87(\mathrm{~B})$ & $261(\mathrm{~F})$ & $379(\mathrm{E})$ & $167(\mathrm{D})$ \\
\hline
\end{tabular}

Thus of all four scenarios, Scenario 3 offers the greatest margin of safety for most people, even though it results in the longest assembly time and the longest travel distance for the population of the RD. Without the use of coupled fire and evacuation modelling this result may not have been immediately apparent as it is somewhat counter intuitive i.e. preferred option involves longest assembly time and greatest travel distance for RD residents.

The safety margins also provide a basis on which to prioritise the warning sequence for the occupants in the various establishments. In the preferred Scenario 3, the population with the shortest safety margin are the occupants of the Pub followed by the occupants of the RD and TRL and finally the BE. Thus if resources are limited, it would be essential to warn the occupants of the Pub first followed by the RD.

\subsubsection{Congestion on Evacuation Routes}

Relatively small amounts of congestion was experienced on the evacuation routes in all scenarios. Since the evacuation took place on roads which were at least 4 meters wide, there was not much congestion experienced by the agents in any of the scenarios. Furthermore, the agents from the different establishments reached the main exit routes at slightly different times reducing the likelihood of generating high congestion levels. The percentage of time spent by the agents in congestion compared to their overall evacuation time for all scenarios is shown in Table 6.

Table 6: Percentage of the time agents spent in congestion compared to their overall evacuation time

\begin{tabular}{|c|c|c|c|c|}
\hline & Scenario 1 (\%) & Scenario 2 (\%) & Scenario 3 (\%) & Scenario 4 (\%) \\
\hline TRL & 7.2 & 5.7 & 7.2 & 5.7 \\
\hline BE & 1.2 & 1.3 & 1.2 & 1.3 \\
\hline Pub & 5.7 & 5.6 & 5.7 & 5.6 \\
\hline
\end{tabular}

The agents from TRL experience the greatest levels of congestion for all scenarios with Scenarios 1 and 3 producing the most severe conditions when they take the direct route to the assembly area. However, when they use the path that takes them through the BE the levels of congestion they encounter are lower due to the fact that their evacuation takes longer and have longer time to spread on the evacuation route. However, in the worst cases of Scenarios 1 and 3 they only waste $7.2 \%$ of their travel time in congestion. The agents from the BE experience very low levels of congestion 1.2\% for Scenarios 1 and 3 and $1.3 \%$ for Scenarios 2 and 4 . This is due to the fact that the relatively fewer agents (200 in total) are distributed in several buildings within the estate. Therefore, 
there is little chance for congestion to build up along the evacuation route. Conversely, the same number of agents that are located in the Pub experience higher levels of congestion at 5.7\% for Scenarios 1 and 3 and 5.6\% for Scenarios 2 and 4 . This is due to these agents exiting from one small building and utilising a single short path $(0.8$ $\mathrm{km})$ to the assembly area. The agents originating from the RD did not experience any congestion in any of the scenarios.

\subsection{Reviewing simulation results in webEXODUS during emergency response}

The version of EXODUS used in the above analysis, which is equivalent to the planning and preparation phase of an emergency was urbanEXODUS. During the emergency response phase, the incident strategic commanders require a more mobile and easier to use version of the evacuation simulation tool. In these applications the webEXODUS interface can be used by operators with little or no knowledge of evacuation simulation software to analyse evacuation procedures during a developing incident. webEXODUS can be accessed over the internet allowing field commanders to specify simulation inputs using a browser, run simulations on the EXODUS engine located on a remote server and view the simulation results. A single aspect of the webEXODUS functionality namely the ability to replay the simulation results on a web browser is shown in Figure 14. The main purpose of this functionality is to allow the user to step through the simulation to gain an understanding of how the pedestrian evacuation is projected to progress during the incident. These figures show snapshots of the simulation progress for one randomly selected simulation from the 10 repeat simulations for Scenario 1 at $10 \mathrm{~min}, 30 \mathrm{~min}, 60 \mathrm{~min}$ and $91 \mathrm{~min}$. Though it is possible to show the evacuation simulation progress at $10 \mathrm{~s}$ time steps, these key time steps have been chosen for discussion in this section as they correspond to time step used in the fire model.

There are three main sections in the webEXODUS interface used to view the simulation progress as a time stepped animation. The main body consists of the base map and the population density overlays. The base map shown is the OpenStreetMap. However, other base map layers can be selected including various versions of Google Maps. The population density contour is seen as dots at the assembly location and at the highlighted (circled) locations. The dots are cells measuring $36 \mathrm{~m}^{2}$ (6 X 6 meters) and their colour represents a heat map based on the density of the agents contained in the cell (e.g. hotter colour, red, for higher densities and cooler colour, blue, for lower densities). The reason behind the selection of this size is based upon the assumption that group behaviour is best observed at this size (Pretorius et al., 2013). The critical locations A, B, C and E are shown as lines on the map labelled accordingly. These lines or critical locations are interactive in that they can be clicked on to bring up a popup showing the total number of agents that have cleared the location during the entire simulation and the number of agents that have cleared them at the current time.

The snapshot in Figure 14a was captured at 10 min after fire ignition i.e. the start of the evacuation. The fire data is provided at approximately 30 minute time steps and hence there is no fire data available at this time. The footer of this interface contains the controls to step through the evacuation simulation. The simulation time, the number of agents that have reached the assembly location and number still evacuating is also shown. If there are any predicted fatalities or agents trapped in the simulation due to a loss of viable escape route they can also be depicted. In this simulation at $10 \mathrm{~min}$, all the agents in the Pub have cleared critical location B and 14 of them have already 
assembled with the rest on their way to the assembly location. Agents from TRL and $\mathrm{BE}$ are clearing safe locations $\mathrm{A}$ and $\mathrm{E}$ and are heading towards to the assembly location. At this time only 14 agents have assembled, with 1206 yet to reach the assembly location.

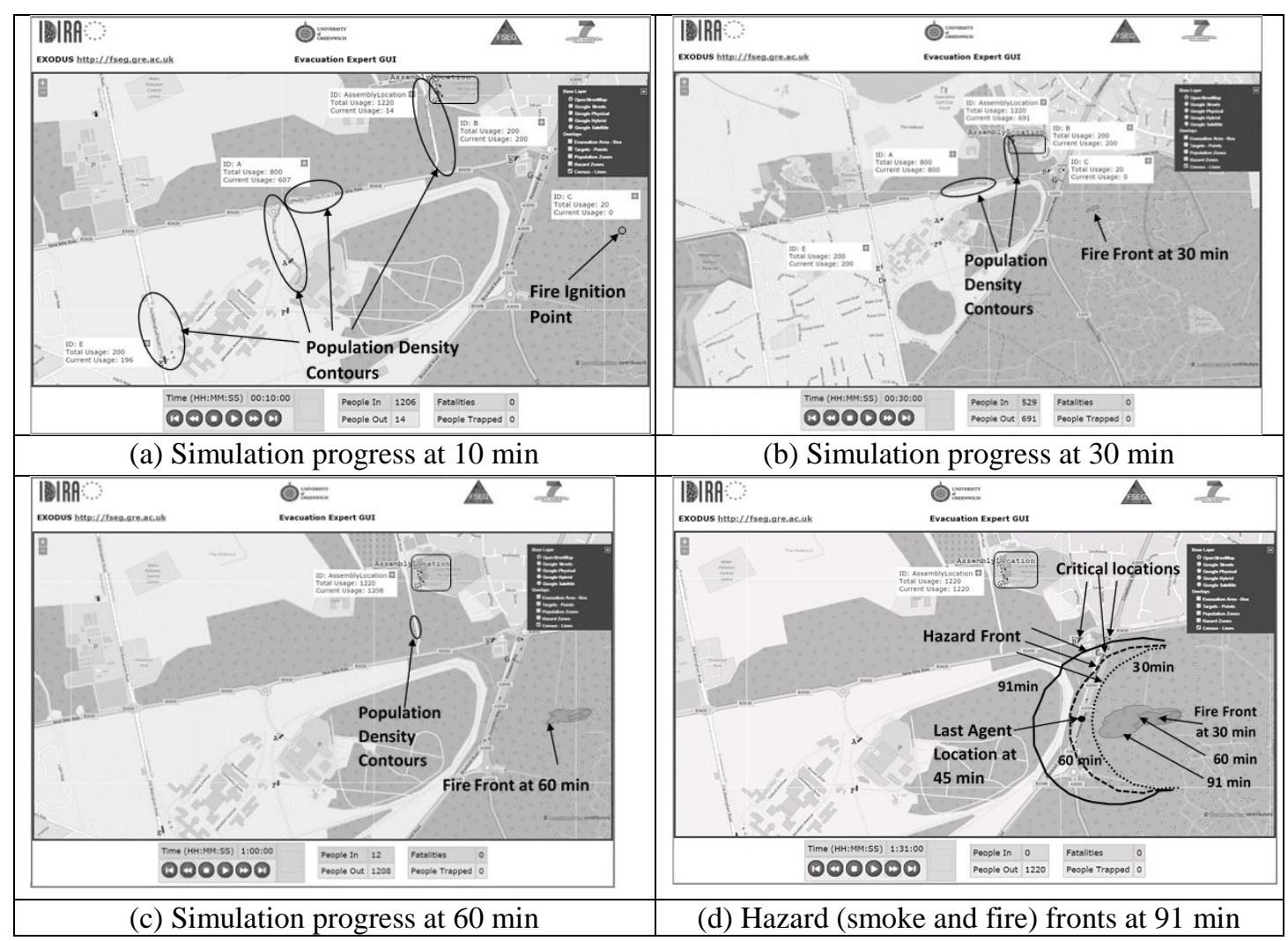
Figure 14: webEXODUS user interface showing progress of evacuation and
hazard front at various times

The simulation progress at $30 \mathrm{~min}$ is shown in Figure 14b. The fire is still small and is not considered to be a threat to the evacuating population. All the agents from the pub have assembled. At this time, 491 agents from TRL have reached the assembly location with the remainder of the TRL population walking along the South Road. The BE agents are walking along the Nine Mile Ride Road. At this time 691 agents have assembled, with 529 yet to reach the assembly location.

The simulation progress at $1 \mathrm{hr}$ is shown in Error! Reference source not found.Figure 14c. Only a handful of agents have not reached the assembly location and are still walking along the South Road. Though the fire front and projected smoke front has now spread closer to the A3095 Road, all the agents are now clear of the advancing front and can be considered to be safe. At this time only 1208 agents have assembled, with only 12 yet to reach the assembly location.

The extent of the hazard front at 30,60 and 91 min after ignition are shown in Figure $13 \mathrm{~d}$. The figure demonstrates how the critical locations and safety margins are determined. In this work the hazard front is considered to be $250 \mathrm{~m}$ ahead of the fire front. Thus by knowing the location of the fire front at a point in time, the location of the hazard front, ahead of the fire front can be determined. At $30 \mathrm{~min}$ it is clear that the fire front is far away from A3095, but the hazard smoke front is some $250 \mathrm{~m}$ ahead of 
the fire front and so is within $45 \mathrm{~m}$ of the road. Thus while the hazard front is approaching the A3095, the road is still considered passable at this time.

The last of the agents from the RD passes the point marked on the A3095 at 45 min. Based on the fire model predictions, the hazard front crosses the A3095 sometime between $30 \mathrm{~min}$ and $60 \mathrm{~min}$. The location at which the hazard front crosses the A3095 could be considered a critical location and this is likely to occur sometime between 30 min and 60 min which may impact the agents from the RD. However, as the fire hazard data was only available in $30 \mathrm{~min}$ time steps it was not possible to identify the critical location on the A3095 and hence it was not possible to determine if the agents from the $\mathrm{RD}$ are considered safe at $45 \mathrm{~min}$. The last of the RD agents reaches critical location $\mathrm{G}$ at $48 \mathrm{~min}$ 6sand critical location $\mathrm{C}$ at $54 \mathrm{~min}$. At $60 \mathrm{~min}$ the hazard front has covered part of the A3095 but the last of the RD agents have reached critical location C by 54 min and so have cleared the threatened part of the A3095. At $60 \mathrm{~min}$, the hazard front is predicted to have reached the vicinity of critical location $\mathrm{G}$. As the last of the agents from the RD cleared this point at $48 \mathrm{~min}$, the safety factor for the RD determined at critical location G is $12 \mathrm{~min}$ (60 min - $48 \mathrm{~min}$ ). Similarly, at $91 \mathrm{~min}$, the hazard front is predicted to have reached the vicinity of critical location $\mathrm{C}$. As the last of the agents from the RD cleared this point at $54 \mathrm{~min}$, the safety factor for the RD determined at critical location $\mathrm{C}$ is $37 \mathrm{~min}$ (91 $\mathrm{min}-54 \mathrm{~min}$ ). Thus on this route, the hazard front follows the RD agents during their evacuation. Assuming that the RD agents are safely through the hazardous region when the hazard front reaches the road (possibly at around $45 \mathrm{~min}$ ), the RD agents are able to stay ahead of the advancing hazard front but must keep moving without reducing their travel speeds.

\section{Limitations and further work}

Urban scale evacuation simulation is still in its infancy and so the software presented in this paper should not be considered a finished product but a prototype. More work is required both in the development of the software tools and in understanding and quantifying the behaviour and performance of people subjected to large-scale disasters. Several important limitations of the work presented in this paper include:

- Understanding and quantifying the response phase behaviour of people (Galea, 2009, Galea et al., 2013 and Galea et al., 2017) in large-scale urban evacuation situations is critical to the validity of urban scale evacuation simulation models. The response phase behaviour is likely to be different for different types of hazardous situations such as wildfire, flood, earthquake and tsunami. Furthermore, this is likely to be culturally and situation dependent (Galea et al., 2013), with people in Hafia Israel potentially behaving differently to a wildfire compared to people in Australia and people in a remote homestead in Australia potentially reacting differently to people in a large urban conurbation in Australia. Other factors such as experience of previous events, training, severity of the perceived threat, prior warning, type of prior warning, social bonds are also expected to exert an influence on response behaviour. The authors are involved in a Horizon 2020 Marie Curie project called GEO-SAFE (Fire Safety Engineering Group, 2016) which intends to collect data concerning response phase behaviour of people subjected to the threat of wildfire in both Europe and Australia which will provide some insight into this issue. Until such data is collected, sensitivity analysis should be undertaken to estimate the impact of response behaviours on model predictions. 
- Physical walking capabilities of pedestrians over long distances (possibly several kilometres), the impact of fatigue and the impact of terrain type, including steepness of grade and nature of surface e.g. paved, gravel, grassy, etc, must be represented within urban scale evacuation simulation models. This extends not just to the physical capabilities of the population but also how the different terrain types can be identified and represented within the geometry of the simulation model. Within the simulations presented in this paper, both fatigue and the nature of the terrain was not represented. Thus the results presented in this paper should be considered 'optimistic'. In collaboration with colleagues in France, ISMANS (Fire Safety Engineering Group 2015a) and Italy, Corpo Nazionale Dei Vigili Del Fuoco (Vigili del Fuoco Comando Perugia, 2016), the authors have started to collect human performance data to address this need.

- Large-scale evacuation situations are unlikely to be performed solely by pedestrians on foot. Road vehicle traffic is a likely component of most urban scale evacuation situations. Road vehicles are likely to be used as a means of population evacuation and may even have an impact on the evacuation of pedestrians. In addition, vehicles will be used to dispatch first responders such as fire fighters to where they are needed and, as in the simulations presented in this paper, provide a means of communicating the need to evacuate to scattered members of the population by dispatching police officers. As part of the IDIRA project (IDIRA end user comments, 2013) the evacuation simulation environment presented in this paper was extensively tested by organisations involved in disaster management who reported that the system was both user friendly and a useful decision support tool for large scale disasters. The major limitation that was identified was the omission of a representation of vehicles within the simulation environment. Clearly, it is desirable to include within urban scale evacuation simulation models a capability to not only represent vehicles, as several models already do (Gulam and Rahim, 2004, Singh et al, 2016 and Halati et al., 2017), but to allow the interaction between vehicles and pedestrians. To address this limitation, the authors have embarked on a research project to include the representation of road vehicles within agent based pedestrian evacuation simulation.

- Clearly, if urban scale evacuation simulation is to be used not only for planning but as part of a decision support tool for incident managers, the software must be able to perform simulations much faster than real time. For the size of the population represented in these simulations (1220 people) and for the size of space represented $\left(1.58 \mathrm{~km}^{2}\right)$, the EXODUS engine was found to be capable of simulating the evacuation about 20 times faster than real time using a standard PC computer. This type of performance, and better, is required for populations not measured in one or two thousand, but in the tens and hundreds of thousands and areas measuring tens or hundreds of square kilometres. It is suggested that further improvements in performance could be achieved using the parallel implementation of the EXODUS engine (Grandison et al., 2017) and with the use of more powerful PC computers.

- Wildfire fire simulation tools such as Prometheus (Tymstra et al. 2010) and Phoenix (Tolhurst et al. 2008) currently only provide an estimation of the location of the fire front. They do not also provide information related to the movement, optical density and composition of fire smoke. Knowledge of the 
presence and concentration of fire smoke is vital for evacuation in wildfires as smoke is likely to make evacuation routes non-tenable long before the flaming fire front. Further development of wildfire fire simulation tools is therefore required before the coupled fire-evacuation analysis can be truly useful as part of the real time decision support tool for incident managers.

- Calculation of the safety margins associated with each population and evacuation route is currently a laborious manual process requiring the running of many coupled fire and evacuation simulations to identify potential critical locations and as such is prone to error. The process of identifying critical locations and safety margins can be automated ensuring that all critical locations associated with evacuation routes are identified and all safety factors computed.

\section{Conclusion}

This paper presents a prototype software system that has been developed to evaluate evacuation procedures during the preparation (urbanEXODUS) and emergency response phases (webEXODUS) of a large scale incident such as a wildfire. The software makes use of open source geospatial vector data (OSM XML) to generate a virtual representation of the physical space through which pedestrian based evacuation occurs. Free and open source web and GIS software is used to develop the web interface which is used to establish a remote connection with the EXODUS engine and integrate with a state-of-the-art web based disaster management system to produce a Common Operating Picture for disaster managers. Furthermore, the software was loosely coupled to the forest fire simulation software Prometheus enabling the potential impact of the fire on the evacuation to be evaluated.

The simulation tool was demonstrated by simulating the evacuation of part of Bracknell UK which was affected by the Swinley fires of 2011. The software, coupled with the output from the Prometheus wildfire simulation software, was used to evaluate four possible evacuation scenarios associated with hypothetical wind changes that could have impacted the fire development during the actual fires. The analysis determined the time required to evacuate the threatened population to a place of safety, the distances travelled by the population, levels of congestion incurred during the evacuation and the safety margins associated with each population centre in each scenario. The analysis identified that two of the scenarios would result in very small safety margins associated with the evacuation of occupants from threatened residential dwellings. The optimal scenario, which resulted in maximum safety margins for all threatened sub-populations was counter intuitive in that it resulted in the maximum assembly time and the longest travel distances for the occupants of the residential dwellings. Use of the software also confirmed the viability of the identified assembly area, prioritised the alerting of the atrisk populations and assisted in prioritising the tasks of the emergency services.

The work demonstrates that the integration of fire simulation with evacuation simulation enables the estimation of safety margins associated with alternative evacuation strategies and thereby assists incident managers in planning phased evacuation strategies. Most importantly, the quantification of safety margins associated with evacuation choices assists incident managers to more reliably select the most appropriate evacuation strategy for the evolving situation. The system can be 
extrapolated to other emergencies such as those associated with floods and earthquakes or manmade terrorist situations. Additional research is required to improve the applicability and reliability of urban scale agent based evacuation simulation including, improving our understanding and quantification of; response phase behaviour, walking behaviour of pedestrians over long distances and different types of terrain, the representation of vehicles and their interaction with pedestrians, the representation of smoke in wildfire simulations and the speed and performance of large scale agent based simulation models.

\section{Acknowledgements}

Project IDIRA (FP7 261726) was funded under the European Union Framework 7 Security mission dealing with Interoperability of data, systems, tools and equipment in case of crisis (SEC-2010.4.2-1). The University of Greenwich authors acknowledge the co-operation of their project partners in undertaking this work and in allowing the project findings to be published. The authors are also indebted Louise Osborn, Emergency Planner, Bracknell Forest Council for assistance in defining the scenarios.

\section{References}

BBC News, 2016. Israel fires: Tens of thousands flee as fires hit Haifa. [online] Available at: <http://www.bbc.co.uk/news/world-middle-east-38088651> [Accessed 30 Dec 2016].

Bernardini, G., D'Orazio, M., Quagliarini, E. and Spalazzi, L., 2014. An Agent-based Model for Earthquake Pedestrians' Evacuation Simulation in Urban Scenarios. Transportation Research Procedia, 2, pp.255-263, http://dx.doi.org/10.1016/j.trpro.2014.09.050.

Careem, M., Bitner, D. and Silva, R.D., 2007. GIS integration in the Sahana Disaster Management System. In: ISCRAM 2007 - Intelligent Human Computer Systems for Crisis Response and Management. Netherlands, 13-16 May 2007. Netherlands: Bartel.

Chicago Tribune, 2016. More than 82,000 people flee Southern California wildfire. [online] Available at: <http://www.chicagotribune.com/news/nationworld/ctcalifornia-wildfire-20160816-story.html> [Accessed 30 December 2016].

Chooramun, N., Lawrence, P.J. and Galea, E.R., 2012. An agent based evacuation model utilising hybrid space discretisation. Safety Science, 50(8), pp.1685-1694, http://dx.doi.org/10.1016/j.ssci.2011.12.022.

Cova, T.J., Dennison, P.E., Kim, T.H. and Moritz, M.A., 2005. Setting Wildfire Evacuation Trigger Points Using Fire Spread Modeling and GIS. Transactions in GIS, 9(4), pp.603-617, http://dx.doi.org/10.1111/j.1467-9671.2005.00237.x.

Cova, T.J. and Johnson, J.P., 2002. Microsimulation of Neighborhood Evacuations in the Urban-Wildland Interface. Environment and Planning A, 34(12), pp.2211-2229, http://dx.doi.org/10.1068/a34251.

Crowhurst, E., 2015. Fire statistics: Great Britain April 2013 to March 2014. London: Department for Communities and Local Government.

Currion, P., Silva, C.D. and Walle, B.V.D., 2007. Open source software for disaster management. Communications of the ACM, 50(3), pp.61-65, http://dx.doi.org/10.1145/1226736.1226768. 
D’Orazio, M., Quagliarini, E., Bernardini, G. and Spalazzi, L., 2014. EPES Earthquake pedestrians' evacuation simulator: A tool for predicting earthquake pedestrians' evacuation in urban outdoor scenarios. International Journal of Disaster Risk Reduction, 10(A), pp.153-177, http://dx.doi.org/10.1016/j.ijdrr.2014.08.002

Drake, J.D. and Worsley, J.C., 2002. Practical PostgreSQL. O'Reilly Media, ISBN: 978-1565928466

Durst, D., Lämmel, G. and Klüpfel, H., 2014. Large-Scale Multi-modal Evacuation Analysis with an Application to Hamburg. In: Weidmann, U., Kirsch, U., Schreckenberg, M (Eds). Pedestrian and Evacuation Dynamics 2012. Switzerland: Springer International Publishing, pp.361-369, http://dx.doi.org/10.1007/978-3-31902447-9_30.

Fire Safety Engineering Group, 2015a. ISMANS inclined plane trials, France 6 March 2015. [online] Available at: <https://www.facebook.com/pg/Fire-Safety-EngineeringGroup-FSEG-

136784013003514/photos/?tab=album\&album_id=1038243406190899> [Accessed 30 Dec 2016].

Fire Safety Engineering Group, 2015b. IDIRA EU FP7 project. [online] Available at: <http://fseg.gre.ac.uk/fire/idira.html> [Accessed 06 Jan 2017].

Fire Safety Engineering Group, 2016. GEO-SAFE EU Horizon 2020 Marie Curie project. [online] Available at: <http://fseg.gre.ac.uk/fire/geo-safe.html> [Accessed 30 Dec 2016].

Galea, E.R., 2009. Evacuation Response Phase Behaviour, Paper No. 09/IM/147, October 2009, University of Greenwich. London: CMS Press. ISBN: 978-1-904521$62-4$.

Galea, E.R., Deere, S.J, Hopkin, C.G., and Xie, H., 2017. Evacuation Response Behaviour of Occupants in a Large Theatre during a Live Performance. Fire and Materials, pp. 1-26, http://dx.doi.org/10.1002/fam.2424.

Galea, E.R., Filippidis, L., Deere, S.J., and Sharp, G., 2013. Behaviour - Security Culture. Human behaviour in emergencies and disasters: A cross-cultural Investigation. Silke Schmidt and Ed Galea (Eds), pp 131-215, 2013, Pabst Science Publishers. ISBN: 978-3-89967-867-3.

Galea, E.R., Hulse, L., Day, R., Siddiqui, A. and Sharp, G., 2011. The UK WTC 9/11 evacuation study: an overview of findings derived from first-hand interview data and computer modelling. Fire and Materials, 36(5-6), pp.501-521, http://dx.doi.org/10.1002/fam.1070.

Galea, E.R., Sharp, G. and Lawrence, P., 2008. Investigating the Representation of Merging Behavior at the Floor Stair Interface in Computer Simulations of Multi-Floor Building Evacuations. Journal of Fire Protection Engineering, 18(4), pp.291-316, https://doi.org/10.1177/1042391508095092.

Gazzard, R., 2014. Summary of Forestry Commission analysis of IRS for Wildfire evidence. [online] Available at: <http://www.figuk.org.uk/conferences/2014/rob_gazzard.pdf> [Accessed March 20, 2015]. 
Gulam, H.B. and Rahim, F.B., 2004. A high fidelity traffic simulation model based on cellular automata and car-following concepts. Transportation Research Part C: Emerging Technologies, 12(1), pp 1-32, http://dx.doi.org/10.1016/j.trc.2002.05.001.

Grandison, A., Cavanagh, Y., Lawrence, P.J. and Galea, E.R., 2017. Increasing the simulation performance of large-scale evacuations using parallel computing techniques based on domain decomposition, Fire Technology, pp.1-40, http://dx.doi.org/ 10.1007/s10694-016-0645-8.

Halati, A., Lieu, H. and Walker, S., 1997. Corsim - Corridor Traffic Simulation Model. In: American Society of Civil Engineers, Traffic Congestion and Traffic Safety in the 21st Century: Challenges, Innovations, and Opportunities. New York: The National Academies of Sciences, ISBN: 0784402434.

Helbing, D. and Johansson, A., 2013. Pedestrian, Crowd, and Evacuation Dynamics. Encyclopedia of Complexity and Systems Science, 16, pp.6476-6495. New York: Springer, http://dx.doi.org/10.1007/978-0-387-30440-3_382.

IDIRA end user comments, 2013. Confidential end user feedback from the IDIRA Twist training meeting 27 October 2013, CNVVF camp base, Italy.

Incident Information System, 2016. Wildfire On The San Bernardino National Forest. [online] Available at: <https://inciweb.nwcg.gov/incident/4962/> [Accessed 30 December 2016].

Klüpfel, H., 2014. Large Scale Multi-modal Simulation of Pedestrian Traffic. Transportation Research Procedia, 2, pp.446-451, http://dx.doi.org/10.1016/j.trpro.2014.09.058.

Lämmel, G., Grether, D. and Nagel, K., 2010. The representation and implementation of time-dependent inundation in large-scale microscopic evacuation simulations. Transportation Research Part C: Emerging Technologies, 18(1), pp.84-98, http://dx.doi.org/10.1016/j.trc.2009.04.020.

Lämmel, G., Nagel, K., and Rieser, M., 2008. Bottlenecks and Congestion in Evacuation Scenarios: a Microscopic Evacuation Simulation for Large-scale Disasters. In: Bazzan, A.L., Klugl, F., Ossowski, S. (Eds). Proc. of 5th workshop on Agents in traffic and transportation, at International Conference on Autonomous Agents and Multiagent Systems, pp. 54-61.

Mordvintsev, A. S., Krzhizhanovskaya, V.V., Lees, M. H. and Sloot, P.M.A., 2012. Simulation of City Evacuation Coupled to Flood Dynamics. In: Weidmann, U., Kirsch, U., Schreckenberg, M (Eds.). Pedestrian and Evacuation Dynamics 2012. Switzerland: Springer International Publishing, pp.485-499, http://dx.doi.org/10.1007/978-3-31902447-9_40.

Neis, P., Zielstra, D. and Zipf, A., 2012. The Street Network Evolution of Crowdsourced Maps: OpenStreetMap in Germany 2007-2011. Future Internet, 4(1), pp.1-21, http://dx.doi.org/10.3390/fi4010001.

Nishino, T., Tsuburaya, S., Himoto, K. and Tanaka, T., 2011. Validation of a Potentialbased Evacuation Model of City Residents in Post-earthquake Fire. In: R. D. Peacock, E. D. Kuligowski, \& J. D. Averill (Eds.). 2011. Pedestrian and Evacuation Dynamics. Springer International Publishing. pp.399-406.

Obe, R. and Hsu, L., 2011. PostGIS in Action. Manning Publications, ISBN: 9781935182269. 
Osaragi, T., Morisawa, T. and Oki, T., 2013. Simulation Model of Evacuation Behavior Following a Large-Scale Earthquake that Takes into Account Various Attributes of Residents and Transient Occupants. In: Weidmann, U., Kirsch, U. and Schreckenberg, M, (Eds). Pedestrian and Evacuation Dynamics 2012. Switzerland: Springer International Publishing, pp.361-369, http://dx.doi.org/10.1007/978-3-319-024479_39.

Osborne, M.J. and Rubinstein, A., 1994. A Course in Game Theory. MIT press, ISBN 978-0262650403

Perez, A.S., 2012. OpenLayers Cookbook, Packt Publishing Ltd, ISBN 9781849517843

Pretorius, M., Gwynne, S. and Galea, E.R., 2013. Large crowd modelling: an analysis of the Duisburg Love Parade disaster. Fire and Materials, 39(4), pp.301-322, http://dx.doi.org/10.1002/fam.2214.

Prinz, R., 2014. Using Google Glass in Crisis \& Disaster Management. [online] Available at: <http://idira.eu/images/GlassCrisis.pdf> [Accessed 30 December 2016].

Pultar, E. Raubal, M. Cova, T.J. and Goodchild, M.F., 2009. Dynamic GIS Case Studies: Wildfire Evacuation and Volunteered Geographic Information. Transactions in GIS, 13, pp.85-104, http://dx.doi.org/10.1111/j.1467-9671.2009.01157.x.

Regional Municipality of Wood Buffalo, 2016. Regional Municipality of Wood Buffalo 2016 Wildfire Recovery Plan. [online] Available at: <http://asset.rmwb.ca/files/RMWB-2016-Wildfire-Recovery-Plan.pdf?v1> [Accessed 30 December 2016].

Siddiqui, A. A. and Gwynne, S.M.V., 2012. Employing pedestrian observations in engineering analysis. Safety Science, 50(3), pp.478-493, http://dx.doi.org/10.1016/j.ssci.2011.10.011.

Silva, F.N.D. and Eglese, R.W., 2000. Integrating simulation modelling and GIS : spatial decision support systems for evacuation planning. The Journal of the Operational Research Society, 51(4), pp.423-430, http://www.jstor.org/stable/254169.

Singh, D., Padgham, L. and Perera, S., 2016. Bushfire BLOCKS for Modelling Community Evacuation. In: Monoghan, M. (Eds), Australasian Simulation Congress. Victoria, Australia, 26-29 September 2016, pp.509-514. Australia: Simulation Australasia, ISBN: 978-0-9925960-2-6.

Smith, T., 2014. Private Communication, 11 August 2014, 16:09.

Teague, B., McLeod, R. and Pascoe, S., 2009. Interim report: 2009 Victorian Bushfires Royal Commission. Victoria: Parliament of Victoria, ISBN 978-0-646-51830-5.

Teague, B., McLeod, R. and Pascoe, S., 2010. 2009 Victorian Bushfires Royal [1Commission Final Report Summary. Victoria: Parliament of Victoria, ISBN 978-09807408-1-3.

The Globe and Mail, 2016. [online] Available at: <http://www.theglobeandmail.com/news/alberta/the-fort-mcmurray-disaster-read-thelatest-weekend/article29930041/> [Accessed 25 Jan 2016].

The New York Times, 2016. As wildfire rage, Israel suggests arson and asks for foreign help. [online] Available at: 
<http://www.nytimes.com/2016/11/24/world/middleeast/israel-fires.html?_r=1> [Accessed 30 Dec 2016].

Tolhurst, K.G., Shields, B. and Chong, D., 2008. PHOENIX: development and application of a bushfire risk management tool. Australian Journal of Emergency Management, 23(4), pp47-54, http://apo.org.au/node/48885.

Tymstra, C., Bryce, R.W., Wotton, B.M., Taylor, S.W. and Armitage, O.B., 2010. Development and Structure of Prometheus: the Canadian Wildland Fire Growth Simulation Model. Alberta: Natural Resources Canada, Canadian Forest Service, Northern Forestry Centre.

Van de Walle, B. and Turoff, M., 2008. Decision support for emergency situations. Information Systems and e-Business Management, 6(3), pp.295-316, http://dx.doi.org/10.1007/s10257-008-0087-z.

Vigili del Fuoco Comando Perugia, 2016. AF3 Project People Evacuation Test 23-072016 Valsorda Gualdo Tadino (Perugia). [online] Available at: <https://youtu.be/64NDuO_WyaY> [Accessed 30 Dec 2016].

Xia, K. and Wei, C., 2008. Study on Real-Time Navigation Data Model Based on ESRI Shapefile. In: The 2008 International Conference on Embedded Software and Systems Symposia, pp.174-178. Sichuan, 29-31 July 2008. Los Alamitos: IEEE Computer Society, http://dx.doi.org/10.1109/ICESS.Symposia.2008.57. 